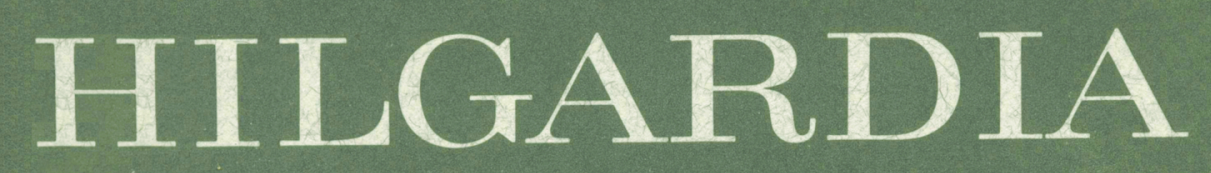

A JOURNAL OF AGRICULTURAL SCIENCE PUBLISHED BY THE CALIFORNIA AGR ICULTURALEXPERIMENTSTATION

Volume 46, Number 8 - November, 1978

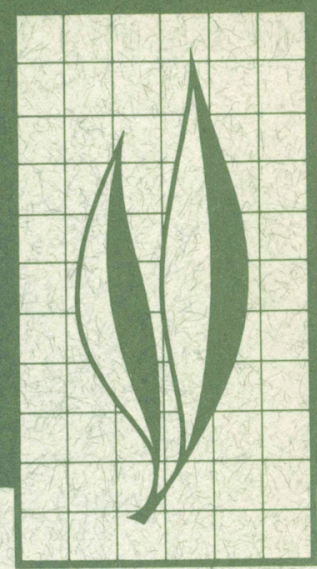

\title{
A Comparision of Sampling Methods for some Arthropod Populations in Cotton
}

K. F. Byerly, A. P. Gutierrez, R. E. Jones, and R. F. Luck 


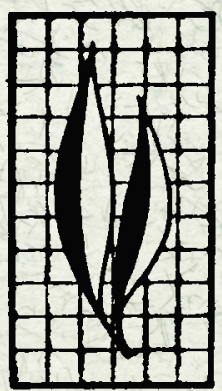

Accurate sampling of arthropod populations in California cotton is essential to the development of integrated pest management strategies. The accuracy of the two commonly used relative sampling methods (i.e., D-vac and sweepnet) is compared to a new, more accurate whole-plant-bag sampling method (WPBS). A decision rule for WPBS is also reported.

\section{THE AUTHORS:}

K. F. Byerly was Graduate Research Assistant, Department of Entomology, Riverside; he is now Research Scientist at CIANO, Cuidad Obregon, Mexico.

A. P. Gutierrez is Entomologist, Division of Biological Control and the International Center for Integrated and Biological Control, Berkeley.

R. E. Jones was Post Doctoral Fellow, Department of Entomology, Davis; she is currently Assistant Professor of Biology, James Cook University, Townsville, Queensland, Australia.

R. F. Luck is Assistant Professor of Entomology, Department of Entomology, Riverside. 


\section{A Comparison of Sampling Methods for some Arthropod Populations in Cotton ${ }^{1}$}

\section{INTRODUCTION}

Sampling animal populations in various ecosystems can be expensive and time-consuming, and in many studies the sampling method used may not accurately estimate densities and natural variability of the populations. The sampling methods used for insects in cotton have been particularly vulnerable to this criticism. For these reasons, this study was undertaken to:

a) develop the whole-plant-bag sampling method (WPBS) to estimate ar- thropod populations in cotton as precisely as possible, and

b) compare WPBS with the more commonly used relative sampling methods-D-vac and sweepnet.

The WPBS method was then used to examine the dispersion of various species within the cotton field and among plants and to develop sampling decision rules. Summaries of the extensive data are available upon request. ${ }^{2}$

\section{REVIEW OF THE LITERATURE}

Population sampling may be either extensive or intensive (Morris, 1960; Strickland, 1961). Extensive sampling usually is used to survey large areas. It may be concerned with such problems as the relative abundance and distribution of insects among fields, their relationship to crop damage, or with the efficacy of some area-wide control measure. Intensive studies, on the other hand, stress continued sampling of a population through time. These data may be used to develop life tables, to estimate changes in population growth parameters, or to determine how the organisms are distributed within the field (e.g., Harcourt, 1969; Morris, 1957; Southwood, 1966; Varley and Gradwell, 1971). Relative sampling devices, such as the insect sweepnet or D-vac, (Die- trick, Schlinger, and van den Bosch 1959) may be adequate for extensive surveys, but may be grossly inadequate for intensive sampling programs. The use of relative sampling methods to estimate arthropod populations in cotton appears to be just such a case (e.g., Sevacherian and Stern, 1972). Perhaps no sampling method will be suitable for all insects, because only a portion of the habitat, or only a few of the life stages, may be sampled with the technique (Southwood, 1966). The statistical principles for analyzing the sample data are well known (Cochran, 1963; Mendenhall, Lyman, and Schaeffer, 1971; Yamane, 1967), but the technical problem of obtaining an absolute sample of all the organisms in a particular area remains unresolved. Morris (1955) gave

\footnotetext{
1 This manuscript was accepted for publication April 10, 1978.

2 The International Center of Biological Control, University of California, Berkeley; 1050 San Pablo Avenue, Albany, California 94706.
} 
six criteria to be met if a sampling method is to be a satisfactory technique for assessing absolute populations:

1. All units must have an equal chance of selection.

2. The sample unit must be stablei.c., continuously available to the insects.

3. The proportion of the insect population using the sampling unit must remain constant.

4. The sample unit should be reasonably small, so that enough units can be examined to provide an adequate estimate of the sample variance.

5. The sample unit should provide good estimates of absolute populations.

6. The sample must be easy to take.

Comparisons of the efficiency of various sampling methods in cotton have been attempted (Davis et al., 1966; Race, 1960; Sheppard and Sterling, 1972; Pieters and Sterling, 1973), but these comparisons were only partially successful because they lacked a suitable approximation of an absolute sample to use as a standard. Leigh, Gonzalez, and van den Bosch (1971) suggested an absolute sampling method for cotton which was used by Gonzalez et al. 1977, but proved too cumbersome for practical ficld use. Smith, Stadelbacher, and Gautt (1976) compared four sampling methods to detect population trends of beneficial arthropods in Mississippi cotton. D-rac, sweepnet, and whole-plant inspection were compared to an "absolute" one employing a $3 \times 3 \times 3$-foot $(.9 \times .9 \times .9 \mathrm{~m})$ Lexan cage. All methods indicated similar seasonal trends in density, when using combined data for all predator species on each sample date. The methods were not compared for precision in estimating population densities nor analyzed as to differences in population trends by species or developmental stage (mature versus immature). Thus, their results were not adequate for determining the "best" method for estimating population densities of beneficial arthropods.

\section{MATERIALS AND METHODS}

This study was done in the summers of 1973 and 1974 , in two fields of at least 20 acres each year (Palla and Bartel fields in 1973; Cave and Bartel fields in 1974). The fields were located in the Rosedale area of the southern San Joaquin Valley, near Bakersfield. The experimental area was restricted to the central part of each field. The rows (columns in Fig. 1) in the cotton field always ran east-west, and an alfalfa field was always situated on the west side of the field. The alfalfa was intended to act as a source of arthropods, which could be carried into the cotton on the prevailing NW winds, especially when the alfalfa was cropped. Insecticide treatments were applied only to the 1974 Cave fields, but insecticide drift from adjacent treated areas may have occurred in the other fields.

The cotton crop was planted during the first half of April. To examine the effect of plant development on the sampling methods, plant size and developmental state were recorded through the season. The number of mainstem nodes, squares, small and large bolls, and open bolls were counted on five 1-meter rows of cotton. In addition, in 1974 the leaf areas of two adjacent plants in each of the meter-row samples were measured with an LI-3000 Portable Leaf Area Meter (Lambda Instruments, Lincoln, Nebraska). Daily maximum and minimum temperatures were obtained from the U.S.D.A. Cotton Research Station, Shafter, California. The amount of physiological time, in degree-days ac- 
cumulating above cotton's developmental threshold of $11.9^{\circ} \mathrm{C}$, was computed using Frazer and Gilbert's (1976) algorithm of Morris and Bennett's (1967) method. All phenologies were plotted on this physiological time scale to standardize comparisons.

WPBS, D-vac and sweep samples, and visual counts were taken weekly in each field, from early July to September.

\section{Sampling and processing techniques}

D-vac samples. A standard backpack D-vac (Dietrick, Schlinger, and van den Bosch, 1959; Dietrick, 1961) was used, but with an intake cone diametcr of $23 \mathrm{~cm}$. One person carried and operated the D-vac, while a second person changed, sealed, labelled, and carried the collecting bags. The samples were taken in the morning after dew on the plants had evaporated, but never later than 10 a.m., since Gonzalez et al., (1971) showed that late morning samples lose reliability. Each sample unit consisted of 50 random suctions along a single row within the sub-plot being sampled. The number of terminals covered by a single suck varied with planting density, but corrections made to allow for this variation are noted in the results section.

Each sample was stored in an ice-box until returned to the laboratory for processing, where arthropods were separated from plant debris using Berlese funnels (Dietrick, 1961). Each sample was left in a funnel for 24 hours, during which time light and heat drove the arthropods into jars containing 70 percent alcohol.

Sweepnet samples. The standard University of California sweepnet was used. It is $40.6 \mathrm{~cm}$ in diameter, with a $66 \mathrm{~cm}$ handle and a $63.5 \mathrm{~cm}$ deep conical bag of heavy cotton cloth.

The sample unit within a sub-plot was 50 strokes across the tops of a single row of plants, taken as early as practicable in the morning. As with the D-vac samples, the number of plants covered by each stroke varied with planting density. As soon as it was taken, each sample was placed in a labelled half-pint (ca. 0.5 liter) glass jar containing 70 percent alcohol.

WPBS. The WPBS technique developed here required that the plant be enclosed in a bag rapidly enough to trap on the plant most all individuals of the species under study. The bags were cylindrical, open at both ends, and made of plastic or organdy. Each had a drawstring to close the end at the base of the plant; the top end was folded over and closed with a rubber band.

The bags were placed over the plants and collapsed around the base 10-14 days before the samples were taken. Two methods were used to do this. The first involved slipping the bag over the outstretched arms of one worker to form a tube, which was then slid over the plant. This procedure was tedious and time-consuming, and sometimes damaged the plant, so in 1974 a $36 \times 152$ $\mathrm{cm}$ cylinder of $4.76 \mathrm{~mm}\left(3 / 16^{\prime \prime}\right)$ rolled aluminum, hinged lengthwise, was used to enclose the plant, and the bag was slid over the cylinder. Using this method, three persons could set 216 bags in about $2 \frac{1}{2}$ hours (with very little plant damage), whereas the same crew required 3 to 4 hours without the cylinder.

Once the bag was collapsed around the base of the plant, the draw-string was pulled until a 3 -inch space was left between the bag and the stem. Then the string was left lying across the row, so that the bag could be easily found when the time came to collect the sample. Placing the bags over the plants in this way disturbed the insects; the delay of several days between setting the bags and collecting the samples allowed the effects of this disturbance to disappear. On the sampling day (early in the 
morning, so that the insects would be cool and relatively inactive) the drawstring was pulled tightly around the mainstem and the top of the bag was then pulled rapidly up, folded over, and sealed with a rubber band to enclose the plant. The bagged plants were then cut near ground level with pruning scissors, and the bags inspected for holes. When three adjacent plants in a row were sampled (see section 3 ) a crew of three persons was used to pull the three bags simultaneously. In this way, sampling one plant did not result in the loss of insects from adjacent plants. About $1 \frac{1}{2} 2$ hours were required for three persons to collect 216 samples.

In 1973, the plants were processed immediately in the field. Each plant was removed from its bag and held over an inverted Berlese funnel top, which covered a five-gallon can. Then the whole plant was carefully aspirated with a modified industrial vacuum cleaner. $\Lambda$ small nylon organdy bag over the $6.6 \mathrm{~cm}\left(3^{\prime \prime}\right)$ intake hose collected the insects. After vacuuming the entire plant, the bottom of the can was also vacuumed. The plant was then discarded, and its tag placed in a vial of 70 percent alcohol, together with the contents of the nylon bag. A gas-driven 110 volt generator powered the vacuum machine.

In 1974, the plants were taken to the laboratory, and two persons processed the samples. One removed the plant from the bag and shook it vigorously into a 121-liter (32 gal.) can; the other vacuumed the plant and the bottom of the can, as before. This procedure proved more efficient (fewer insects escaped) and required about half the man-hours.

\section{Sorting and counting samples}

The alcohol-preserved samples were stored, and counted as time permitted. The following species were classified simply as juvenile or adult: Chrysopa carnea Stephens, Orius tristicolor (White), Nabis americoferus Carayon, Lygus hesperus Knight, Collops vittatus (Say), Notoxus calcaratus Horn. Geocoris pallens Stål and G. punctipes (Say) were classified as to sex and instar. Spiders were counted, but different species and stages were not differentiated. Eggs of Geocoris spp. and Chrysopa spp. also were counted.

\section{Location and arrangement of samples within the field}

Each experimental field was divided into 36 plots, in a $6 \times 6$-foot grid pattern. Each plot comprised 12 rows of cotton which ran for one-sixth the length of the field (about $33.5 \mathrm{~m}$ ). The numbering system for the plots is shown in Fig. 1A; each plot is characterized as belonging to a particular row ( $\mathrm{A}$ to $\mathrm{F}$ ), column ( 1 to 6$)$ and "ring" $(\bigcirc \otimes \bullet)$. The twenty plots on the edge of the ficld belong to the outermost or $\bigcirc$ "ring," the next twelve outermost plots to the $\otimes$ ring, and the four central plots to the ring. This classification by column, row, and ring was used to test for systematic within-field differences in insect densities.

D-vac and sweep samples. In both 1973 and 1974, D-vac and sweep samples were taken each week from the six plots next to the adjoining alfafa field. One sample was taken from each plot, except in the 1973 Bartel field, where two were taken. In 1974, five additional samples were taken each week in each field, sub-plots chosen with a random number table.

The row of plants sampled within each plot was also chosen at random with the constraint that the selected row could not be one of the middle two rows in the plot. The two rows were used for the WPBS.

WPBS. Six plants were sampled each week from the two middle rows of cotton in each plot. Except in the 1974 Bartel field, the sampled plants were 
(A)

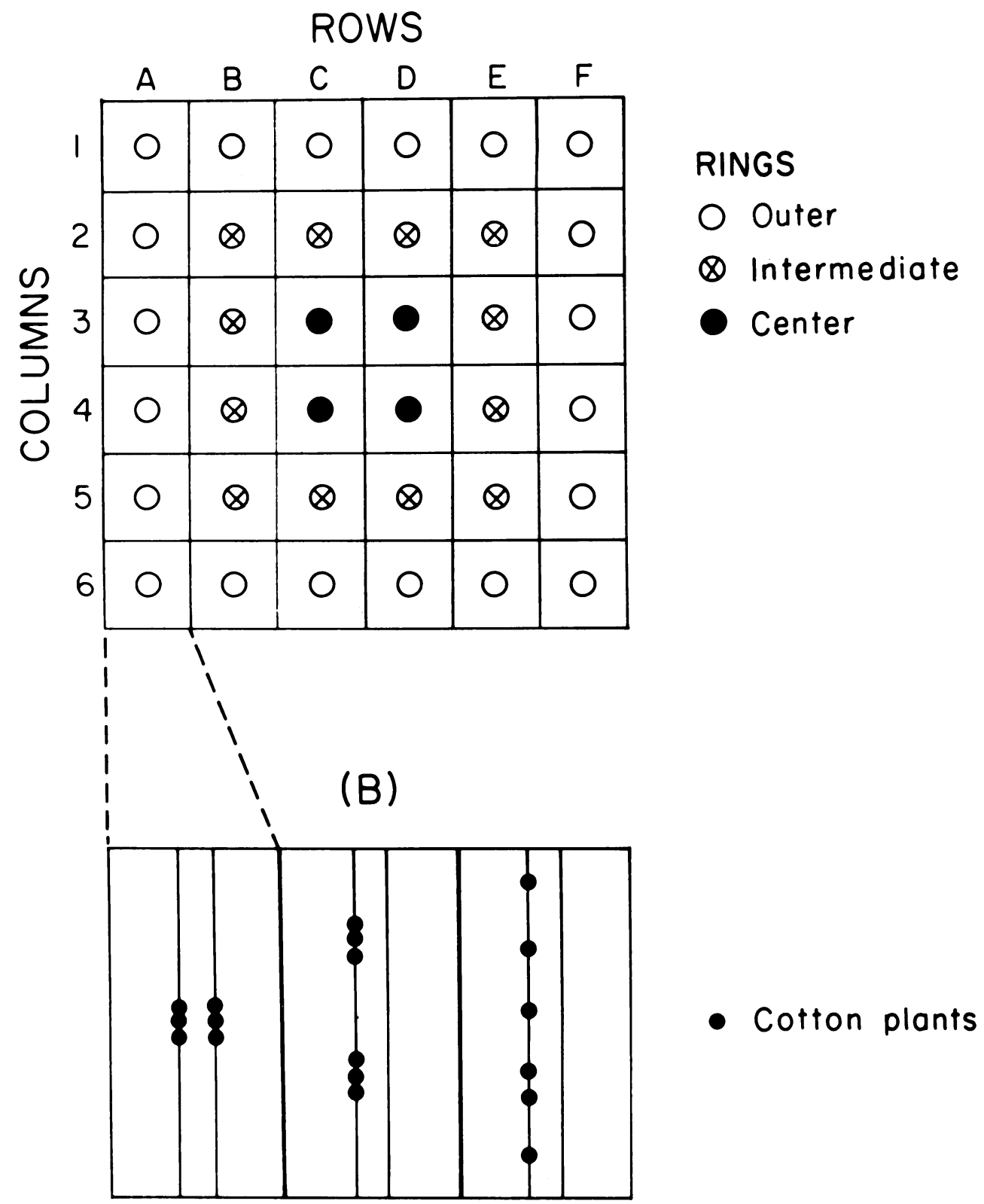

Fig. 1. Plot design : (A) Distribution and classification of sub-plots within the field. (B) Distributions of whole-plant samples within a sub-plot. 
arranged as shown in Fig. 1A. Three adjacent plants in each of the two rows were selected so that the three sampled plants in one row were directly opposite those in the other. On one sampling date in 1973, eight plants rather than six were taken from each plot.

Three different sampling arrangements were used simultaneously in the 1974 Bartel field:

1) three adjacent plants in each of two adjacent rows, as described above (Fig. $1 \mathrm{Ba}$ );

2) three adjacent plants from each of two randomly-chosen positions in the same row (Fig. 1Bb);

3) six widely separated plants from the same row (Fig. 1Bc) - this arrangement was the fastest and easiest to set up and collect.

In the last two samples of 1973 , some plots were not sampled because the plants had been severely defoliated by mite infestations and poor irrigation practices. A total of at least 216 plants (36 plots $\times 6$ plants per plot) were sampled in each field each week.

\section{Analysis of within-field distributions}

Besides looking for systematic variations in insect numbers within the field (using the ring-column-row classification described previously), the degree of aggregation exhibited by each species was studied. The technique used was Iwao's (1968) regression method. This involves plotting "mean crowding" (Lloyd, 1967) against mean density per quadrat or sample, and estimating the slope $(\beta)$ and the intercept $(\alpha)$ of the regression line fitted to this data. (The relationship between the two is almost always linear.) "Mean crowding" (苂) estimates the mean number of other individuals per quadrat individual, and may be defined as:

$$
\ddot{m}=m+\sigma^{2} / m-1
$$

where $m$ and $\sigma^{2}$ are the population mean and variance. The sample estimate of $m$ may be obtained by using the sample estimates of mean and variance ( $x$ and $\mathrm{s}^{2}$ ) in place of $\mathrm{m}$ and $\sigma^{2}$. When the intercept $\alpha=0$, the slope may be estimated from a single point as Lloyd's (1967) "patchiness" index, $\frac{*}{\mathrm{x}} / \overline{\mathrm{x}}$. The regression method has the advantages that it is designed for use where data from a range of population densities is available; and that it provides some information about the form of any aggregation which occurs. The value of $(\alpha+1)$ estimates the "index of basic contagion"; i.e., $\alpha=0$ when the basic component of the distribution is a single individual, $\alpha>0$ when the population is made of cohesive groups (e.g., egg masses or colonies). The regression coefficient $\beta$ then estimates the degree to which these basic units are aggregated: $\beta$ equals unity if they are randomly distributed, and is larger or smaller than unity when the units are overdispersed or underdispersed, respectively. Iwao and Kuno (1971) describe how these methods are related to other commonly used techniques for describing dispersion.

This method, like other similar techniques, must be applied with caution. Two problems may occur. The first is that we cannot accurately estimate the parameters of a regression line when the range of $\mathrm{x}$ values is small relative to the variance in $y$ about the regression line. In practice, to obtain useful estimates of $\alpha$ and $\beta$ we will usually need a several-fold difference between the smallest and largest values of $\bar{x}$. The second concerns the problems of estimation at low population densities. Recall that the formula for crowding is

$$
\text { * }=\overline{\mathrm{x}}+\mathrm{s}^{2} / \overline{\mathrm{x}}-1
$$

Thus when $\overline{\mathbf{x}}$ is small, small changes (or small errors of estimation) in the value of $\mathrm{s}^{2} / \mathrm{x}$ will have a proportionately large effect on the value of $\ddot{\mathbf{x}}$, but when 
$\bar{x}$ is large, small errors in $\mathrm{s}^{2} \sqrt{\mathrm{x}}$ will have little effect. At very low population densities, therefore, the estimates are very sensitive to the accuracy of the estimate of population variance, and as such, are liable to error.

\section{RESULTS}

\section{Crop growth and phenology}

Both the cotton plants and the arthropod populations that live on them change through the season. As the plants grow, they provide more places for the arthropods to disperse. The combined result of plant growth and animal dispersion greatly affects the efficiency ${ }^{3}$ of most sampling methods. Characteristically, the plants grow rapidly until the canopy closes or carbohydrate stress induced by high boll demands occurs (c.f. Gutierrez et al., 1975). This occurs during mid-summer and coincides with the peak of squaring. Late in the scason, plants may collapse from the weight of maturing fruit, or be blown down by wind.

This phenology is likely to influence sampling efficiency in the following ways:

1. When the plants are small and the canopy quite open, all methods are expected to be relatively efficient.

2. As the canopy begins to close, the D-vac and sweep methods tend to sample only the upper part of the plant, and so become less efficient.

3 . When the plants begin to collapse, none of the methods is likely to provide adequate estimates of population size.

The effects of these factors are apparent in the graphical comparisons of the data reported below. These difficulties greatly hinder efforts to develop conversion factors for equating samples taken using D-vac and sweepnet to WPBS estimates. These are discussed later in the section on location and arrangement of samples within the field on page 272 .

\section{Efficiency of relative methods compared to WPBS method}

Graphical comparisons of the results of the sampling methods are made for each predator (or pest) group for both their juvenile and adult stages. The effects of species-specific biologies and the cotton's growth stage are discussed where appropriate to help explain differences among sampling methods. All comparisons are made on a 50-plant basis. Phenological data are presented in the text only for the 1974 Bartel field, since the results from other fields were similar. (Data ${ }^{4}$ from other fields and years are presented in tables 2 to 7 , and figures 3 to 23 , and are discussed in the text only if required to illustrate a particular point.) The only departure from this format is that for comparison of visual Geocoris spp. egg counts with WPBS egg counts.) Table 1 presents a qualitative summary of the adequacy of the three sampling methods for estimating the densities of various immature and adult arthropods found in cotton.

Geocoris spp. Egg counts. Figure 2 compares WPBS and visual counts in the 1974 Bartel field. Geocoris females prefer to lay eggs in the upper half of the plant, and they are easily found. Both methods should provide similar estimates of population size, since both sample the entire plant. But systematic

\footnotetext{
"The term "sampling efficiency" is used here to connote deviation in "catchability" of the various arthropods from some optimal situation (i.e., in practice, from the WPBS or "absolute" estimates).

- Data, too extensive to report here, are available from the Divisions of Biological Control, University of California, Berkeley and Riverside.
} 
TABLE 1

QUALITATIVE EVALUATION OF THE THREE SAMPLING METHODS

\begin{tabular}{|c|c|c|c|c|c|c|}
\hline \multicolumn{7}{|c|}{ Qualitative evaluation of sampling methods* } \\
\hline \multirow[b]{2}{*}{ Species } & \multicolumn{2}{|c|}{ WPBS $\dagger$} & \multicolumn{2}{|c|}{ D-vac } & \multicolumn{2}{|c|}{ Sweepnet } \\
\hline & Immatures & Adults & Immatures & Adults & Immatures & Adults \\
\hline Geocoris spp. & $\mathbf{A}$ & $\mathbf{A}$ & B & B & $\mathrm{C}$ & $\mathbf{C}$ \\
\hline Orius spp. & $\mathbf{A}$ & $\mathbf{A}$ & B & C & O & C \\
\hline Nabis spp. & $\mathbf{A}$ & $\mathbf{A}$ & B & C & C & C \\
\hline Chrysopa spp. & $\mathbf{B}$ & $\mathbf{A}$ & B & C & O & C \\
\hline Lygus spp. & $\mathbf{A}$ & $\mathbf{A}$ & $\mathbf{B}$ & $\mathbf{C}$ & B & $\mathbf{C}$ \\
\hline Spiders & $\mathbf{A}$ & $\mathbf{A}$ & C & C & 0 & $\mathbf{0}$ \\
\hline
\end{tabular}

$* \mathbf{A}=$ Good ; $\mathbf{B}=$ Poor $\mathbf{C}=$ Very Poor.

$\dagger$ Whole-bag plant samples.

discrepancies occurred throughout the season, probably because a small constant fraction, not removed from the plant using WPBS, was included in the visual counts when plants were small. As plants became bushier and more difficult to search, visual counts missed an increasingly larger proportion of the population. Consequently, WPBS gave the most reliable estimates of egg populations later in the season. D-vac and sweepnet samples were worthless throughout. Comparison of WPBS

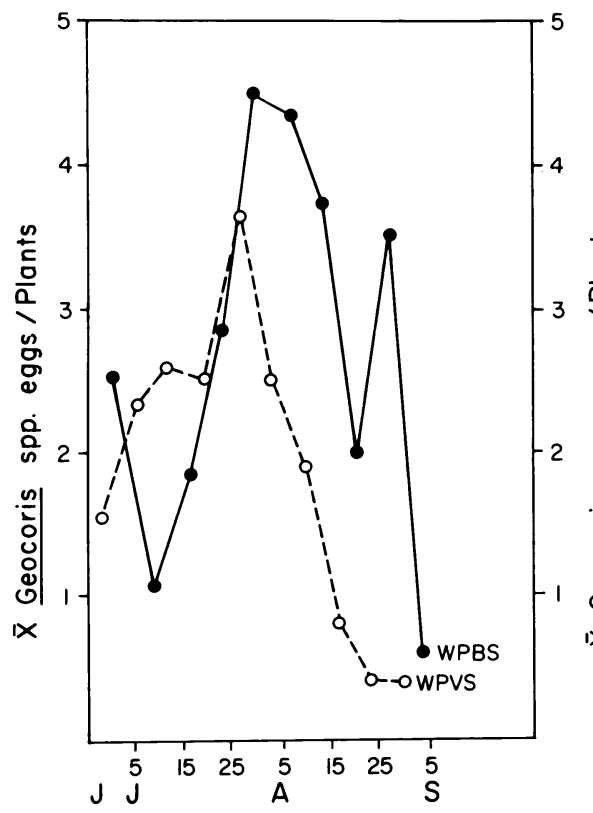

Fig. 2. Comparison of egg density estimates obtained using visual counts and whole plant bag samples (WPBS). averages to visual count averages yielded the following regression parameters: $\mathrm{a}=3.27, \mathrm{~b}=.1754, \mathrm{r}^{2}=.0268$. The predictive value of the regression was extremely poor.

Immatures and adults. Geocoris pallens and to a lesser extent $G$. punctipes are found in cotton and are thought to be important natural enemies of several pests. (c.f. van den Bosch and Hagen, 1966). Figure 3a,b shows that D-vac and sweepnet samples grossly underestimated population densities of immatures and adults, compared to WPBS. The discrepancy became greater as the season progressed and the plants got larger. Although D-vac samples mimicked phenologies better than sweepnet samples, neither worked well. Poor performance of these relative methods indicated that much of the Geocoris population was elsewhere than the top of the plant, and consequently their catchability by these methods was low.

Orius tristicolor. Figure 4a,b depicts the population trends for Orius for the three sampling methods. Both relative methods poorly estimated the densities of immatures. This was probably because the nymphs tended to inhabit the inside of fruiting bracts and other inaccessible parts in the middle of the plant, where they were not likely to be dislodged by sweeping or simple suction.

The $D$-vac gave better estimates of adult densities than did the sweepnet, but it was still unreliable. WPBS may 

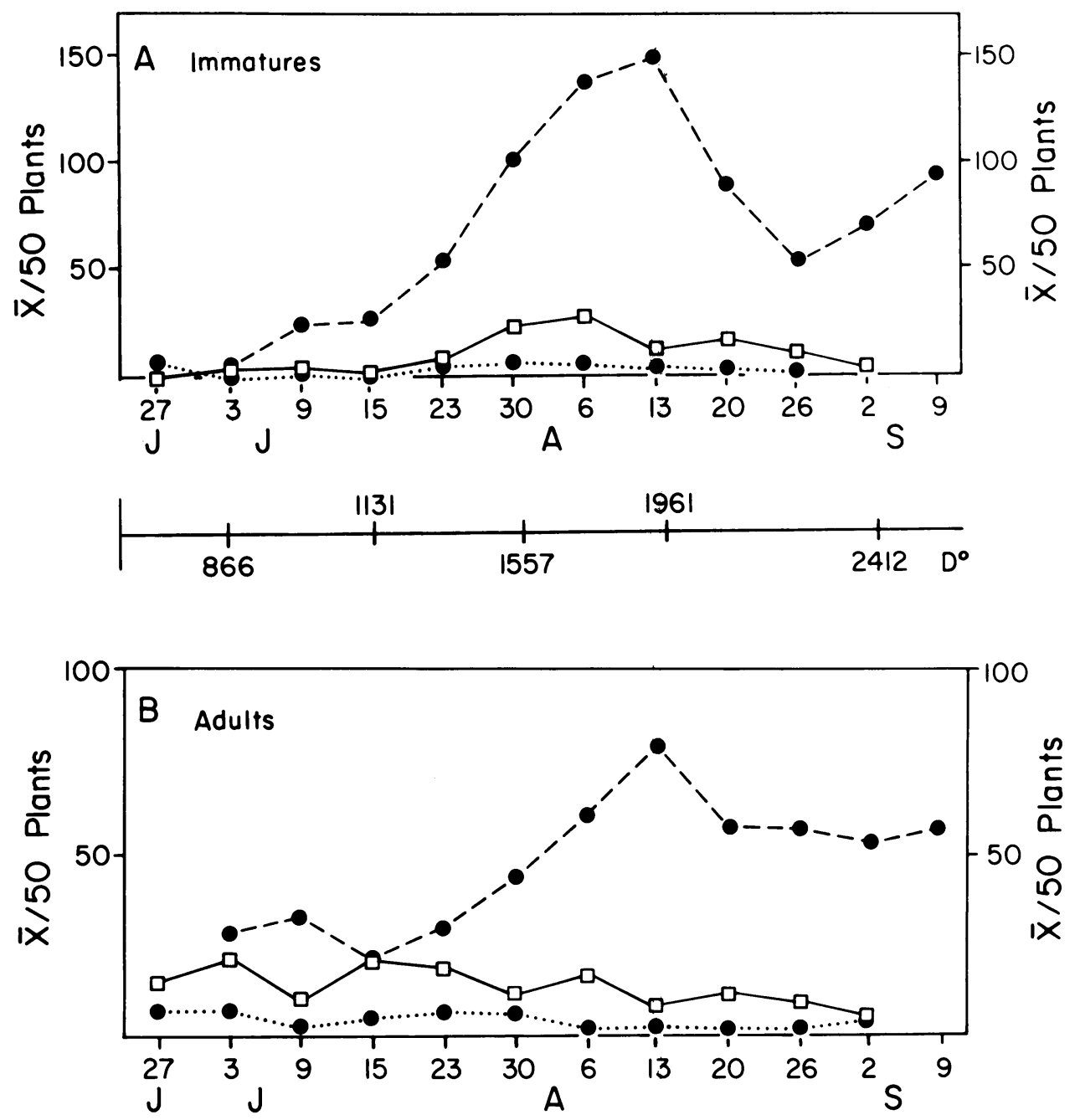

Fig. 3. Comparison of population density estimates of Geocoris spp. obtained using sweepnet (. . ...... ), D-vac ( data from the Bartel 1974 Field.

also underestimate adult densities slightly, since this stage is an active flyer, and a few invariably escaped when samples were being processed in the laboratory.

Nabis americoferus. Figure 5a,b shows the population trends of Nabis spp. immatures and adults respectively for the three sampling methods. Sweeping barely detected either immatures or adults, while D-vac counts tended to mimic theWPBS phenologies of immatures at the beginning of the season, although greatly underestimating their numbers. The poor performance of the relative methods is not surprising since this species prefers to live in the lower strata of the plant.

Chrysopa carnea. Both relative methods were grossly inadequate for Chrysopa immatures; barely detecting their presence even when they occurred at 

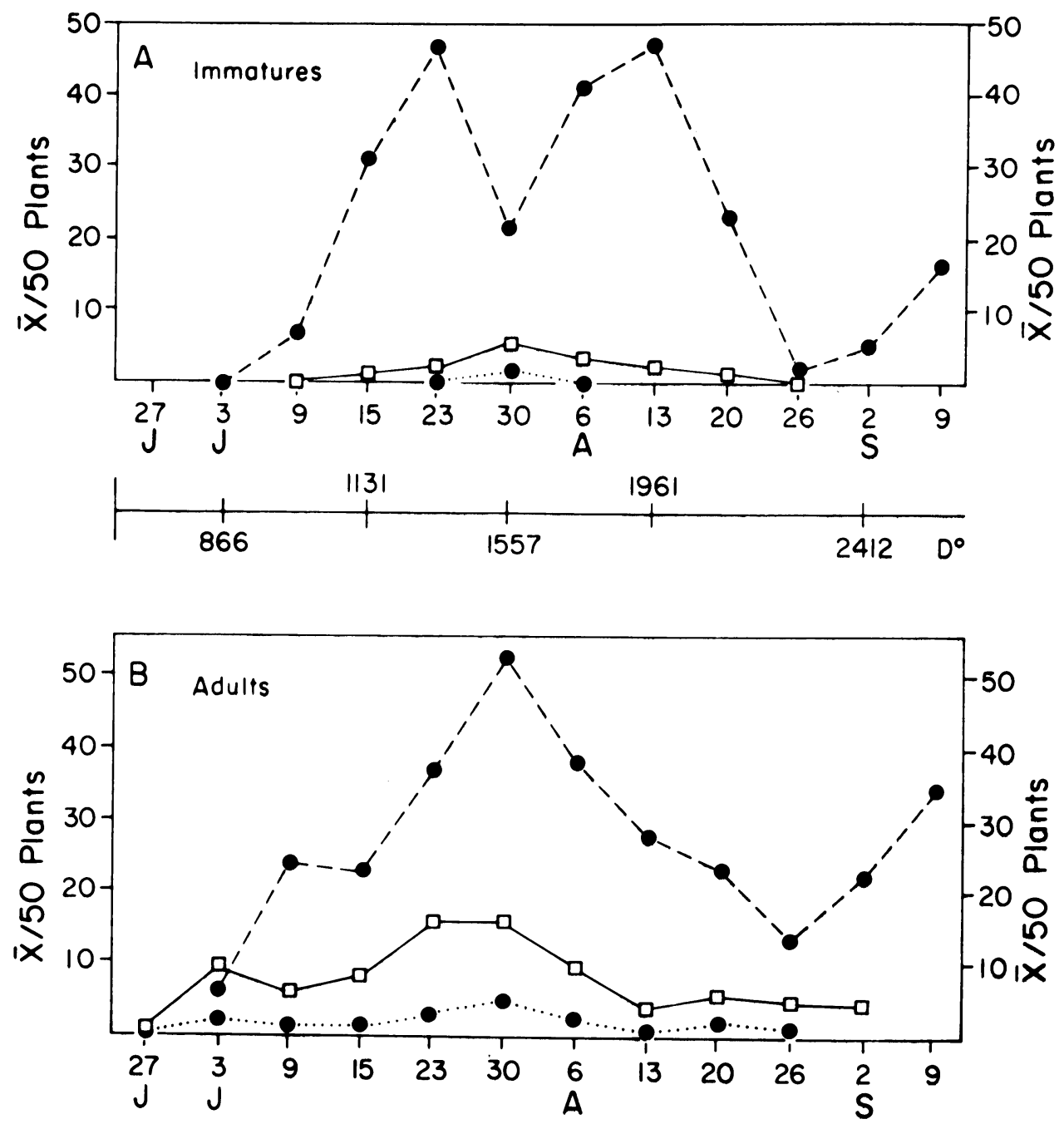

Fig. 4. Comparison of population density estimates of Orius tristicolor obtained using sweepnet $(. . . .$.$) , D-Vac ($ using data from the Bartel 1974 field.

high densities during the latter part of the season (Fig. 6a). This is in sharp contrast to the WPBS method which appeared to provide good estimates.

Lacewing adults are usually active at night when temperatures are low, and are not usually immobilized by early morning summer temperatures. For this reason, WPBS counts did not give absolute estimates of adult densities, as many escaped when the samples were collected in the field or processed in the laboratory. Thus, there was a less reliable, and no "absolute" standard to which the D-vac and sweepnet techniques could be compared.

Spiders. Several species of spiders (e.g., lycosids and web-spinners) are commonly found in cotton, and are thought to be important predators of several important pests. Because several species are involved, results re- 

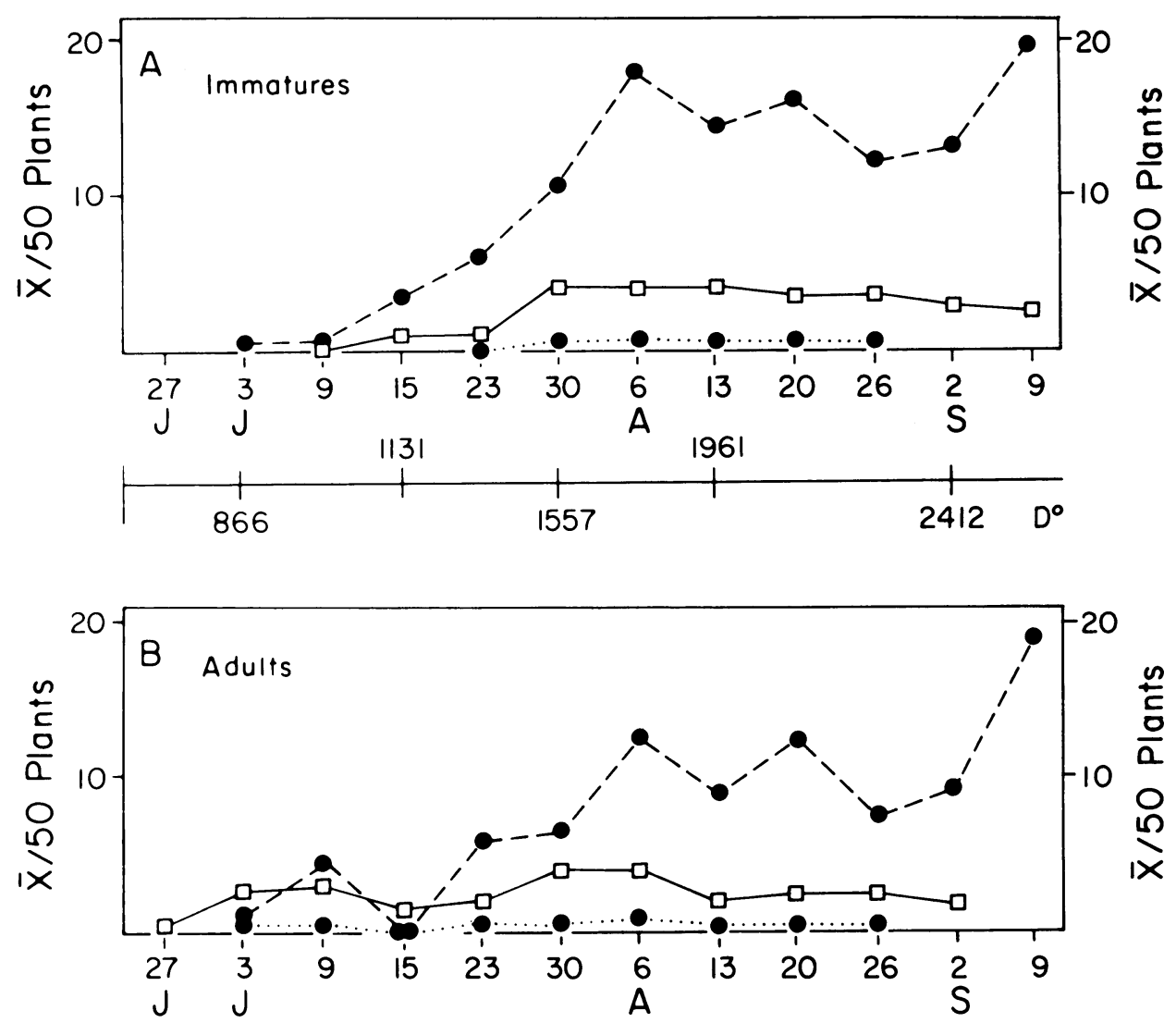

Fig. 5. Comparison of population density estimates of Nabis americoferus obtained using sweepnet (.......), D-vac (—), and whole plant bag samples (WPBS) (- - -) using data from the Bartel 1974 field. (Sweepnet not shown.)

ported here are only suggestive. Figure 7 depicts the population trends for spiders using the three sampling methods. The relative methods almost completely failed to detect spiders, probably because these organisms tend to be near the bottom of the plant. Only the WPBS method appeared to catch spiders. Some of these species, however, may be overestimated because they may utilize the collapsed bag at the base of the plant.

Notoxus calcaratus. This small antlike beetle is often very abundant in California cotton fields. Its feeding habits are not well understood, but the adult will eat plant exudates. Figure 8 shows adult population trends using the three sampling methods, and again these results show that WPBS counts provided the best estimates for adult densities, while the other methods, especialy sweepnet counts, almost completely failed to detect their presence.

Lygus hesperus. This species is one of the key economic pests in California cotton, and considerable sampling using D-vac and sweeping is conducted annually to determine when it has reached the economic threshold (Sevacherian and Stern, 1972). Figure 9a,b depicts population trends for Lygus bug immatures and adults, respectively, using the 

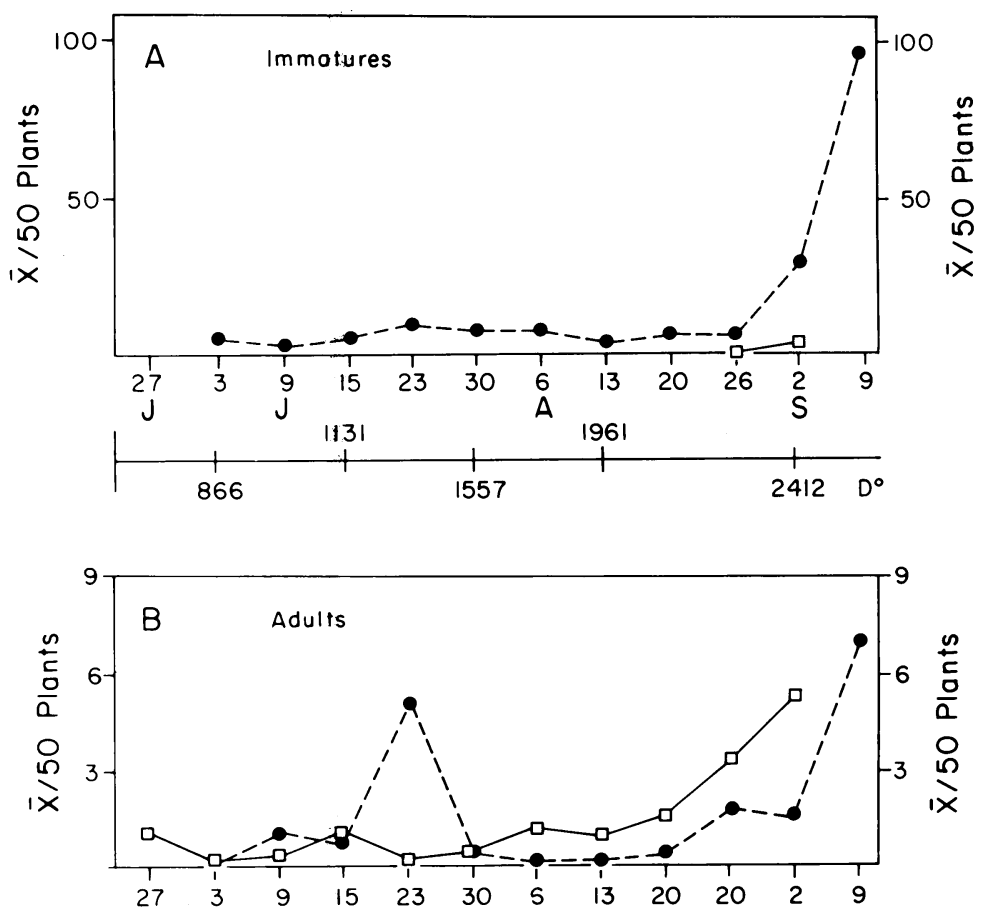

Fig. 6. Comparison of population density estimates of Chrysopa carnea obtained using sweepnet (.......), D-vac (using data from the Bartel 1974 field.

three sampling methods. Both relative methods, while mimicking the changes in population density of immatures and adults obtained using the WPBS method, were consistently low. The sweepnet generally provided poor population estimates, especially for immatures, while the D-vac gave good estimates of adult, but not of nymphal, densities. Our results indicated that the sweepnet, the most common method for determining the population size of this pest, is the least satisfactory. However, because the same population trends were suggested by all three methods, D-vac counts, and to a lesser extent sweep counts, may be used to estimate the "absolute" (WPBS) numbers of individuals present.

\section{Estimating a conversion factor to transform sweepnet and D-vac counts to WPBS counts}

Two aspects must be considered when estimating the appropriate general factor for converting estimates of relative population size to estimates of absolute population size: (a) a correction for the number of plants sampled by each method, and (b) estimating the conversion factor from the corrected counts. These are described below.

(a) Each stroke of the sweepnet or placement of the suction cone may sample more than one plant $(n \geq 1)$; the number $(n)$ is greatly influenced by plant density.

The relative samples consisted of 50 sweeps or suctions; hence to convert 


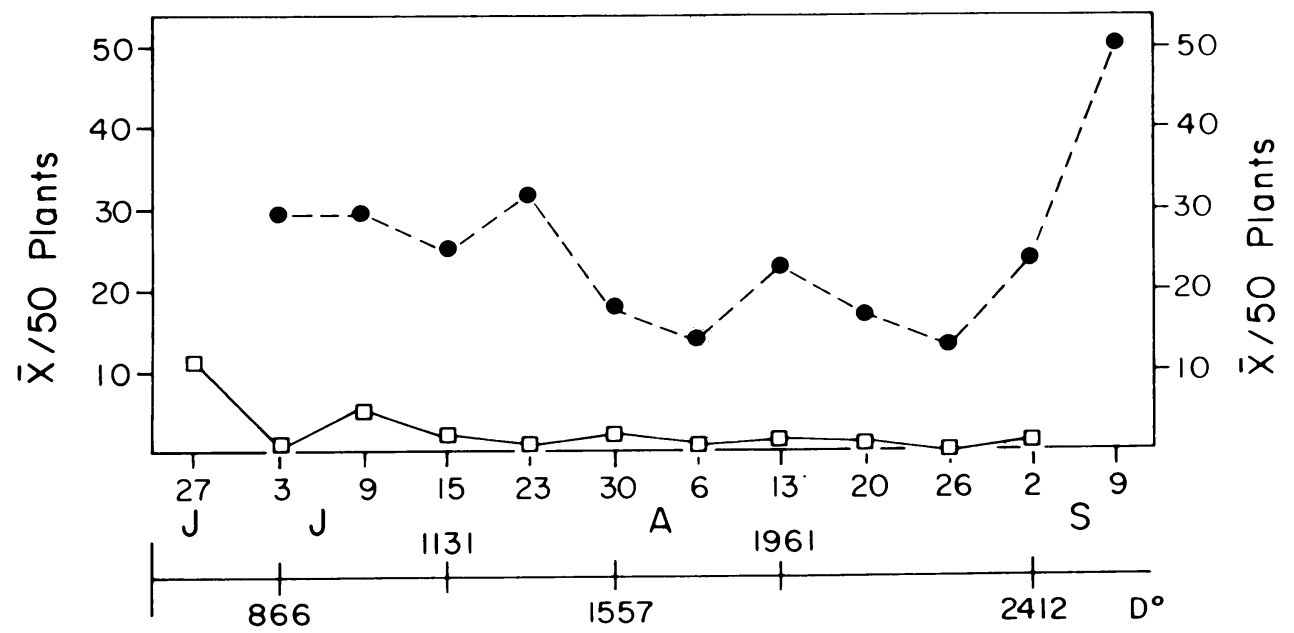

Fig. 7. Comparison of population density estimates of spiders obtained using sweepnet (........), D-vac ( using data from the Bartel 1974 field.

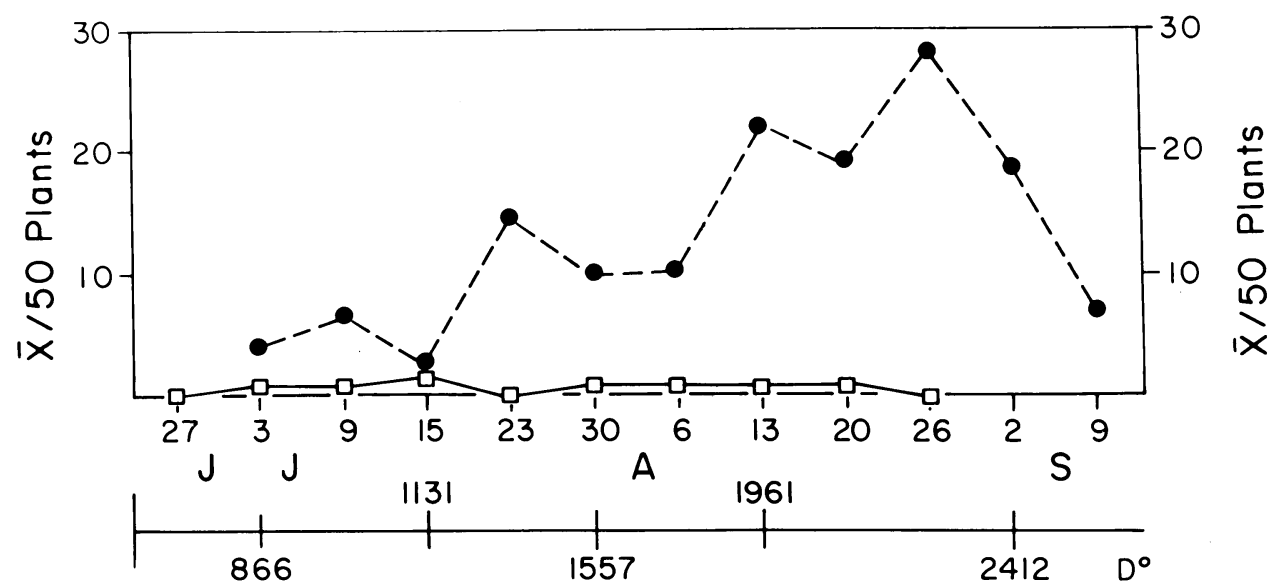

Fig. 8. Comparison of population density estimates of Notoxus spp. obtained using sweepnet (.......), D-vac (—), and whole plant bag samples (WPBS) (- - - ), using data from the Bartel 1974 field.

them to a 50-plant basis, the sample estimates must be multiplied by a correction factor $\left(\mathrm{C}_{\mathrm{i}, \mathrm{k}}\right)$ where

$\mathbf{C}_{\mathrm{i}, \mathrm{k}}=1 /[$ (diameter in meters of net or cone) (plants/meter row)]

where $\mathrm{i}$ is the $\mathrm{i}^{\text {th }}$ field and $\mathrm{k}$ is the $\mathrm{k}^{\text {th }}$ method. The diameter of the sweepnet is $0.41 \mathrm{~m}$, while that of the suction cone is $0.23 \mathrm{~m}$. Table 2 gives the $\mathrm{C}_{\mathrm{i}, \mathrm{k}}$ for each test field. The correction assumes the density is at least $3 /$ meter and are evenly distributed in the path of the device.

(b) If the relative methods sample some proportion $b^{*}$ of the total (WPBS) population, the appropriate relationship should then be the slope regression of the corrected $\left(R_{c}\right)$ per plant counts on WPBS counts taken the same day, i.e.: 

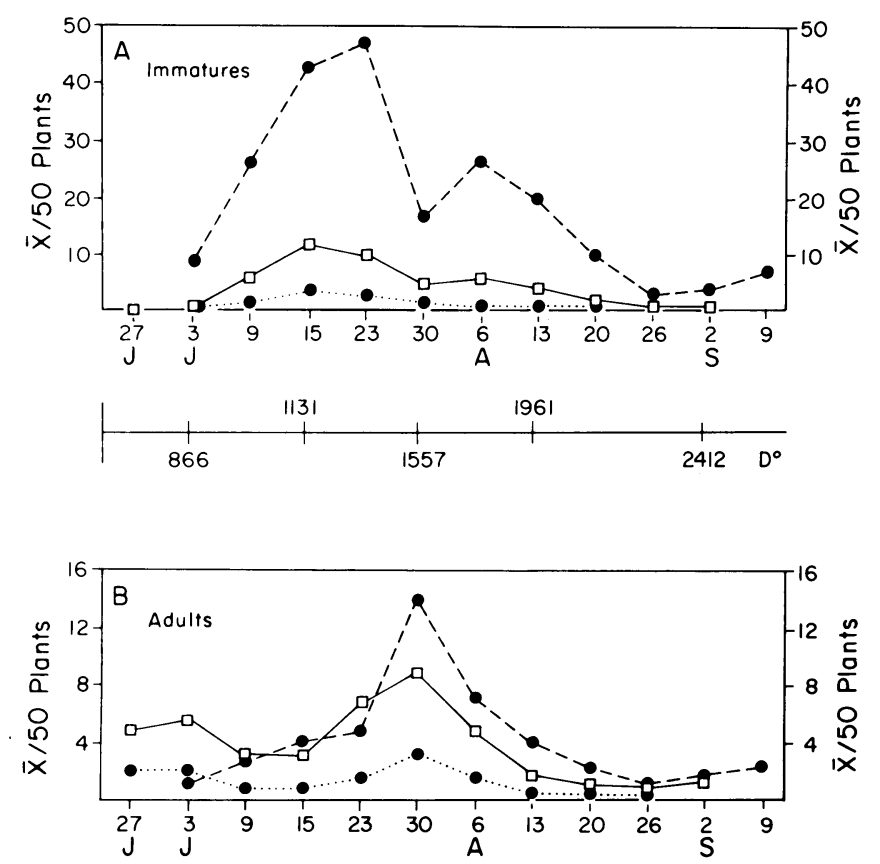

Fig. 9. Comparison of population density estimates of Lygus hesperus obtained using sweepnet (......), D-vac (—), and whole plant bag samples (WPBS) (- - - ), using data from the Bartel 1974 field.

$$
R_{c}=a+b^{*} W P B S
$$

Separate regressions were calculated for adults and immatures.

Only the relative counts for Lygus showed any degree of correspondence to those obtained via the WPBS method. For other species, regression analysis of WPBS counts on relative counts in individual fields were difficult to interpret. The results were quite variable, the sample sizes small, and generally had low predictive value. The re- gression parameters for all fields pooled are shown in Table 3 ; the $\mathrm{r}^{2}$ values show that only the regression for Lygus gave any consistent useful degree of prediction. The explained variance for Lygus samples was greater for the D-vac than for the more commonly-used sweepnet method.

Figure 10 shows a plot of the Lygus data for the 1974 Bartel field for both relative methods. The regressions were forced through the origin, since $a$ was

TABLE 2

CORRECTION FACTORS $\left(c_{i, k}\right)$ * FOR CONVERTING D-VAC AND SWEEPNET SAMPLE COUNTS TO 50-PLANT COUNTS FOR ALL FIELDS, WHERE i IS THE SUBSCRIPT FOR FIELD AND k FOR SAMPLING METHOD

\begin{tabular}{lccc}
\hline \hline $\begin{array}{l}\text { Field name and } \\
\text { index value (i) }\end{array}$ & $\begin{array}{c}\text { Plant density/ } \\
\text { meter row }\end{array}$ & $\begin{array}{c}\text { Correction factors } \\
\text { D-vac } \\
\mathbf{k}\end{array}$ & $\begin{array}{c}\text { Sweepnet } \\
\mathbf{k 2}\end{array}$ \\
\hline Palla 1973 $(\mathrm{i}=1)$ & 6.60 & .6721 & .3744 \\
Bartel 1974 $(\mathrm{i}=2)$ & 12.19 & .3645 & .2058 \\
Cave 1974 $(\mathrm{i}=3)$ & 6.80 & .6433 &. $\mathbf{3 6 2 7}$ \\
Bartel 1974 $(\mathrm{i}=4)$ & 10.00 & .4400 &. $\mathbf{2 4 6 7}$ \\
\hline
\end{tabular}

* Note that the resultant values must be divided by 50 to convert the respective counts to a per-plant basis. 
not significantly different from zero. This makes biological sense since a zero "absolute" count (WPBS) should produce a zero relative count. Hence, the appropriate factor is the slope $b$. (The value of $r^{2}$ then no longer measures the fraction of the sample variance accounted for by the regression line.) The conversion model is thus:

$$
\mathrm{WPBS}_{\mathrm{i}}=\mathrm{C}_{\mathrm{i}, \mathrm{k}}^{-1} \mathrm{~b}_{\mathrm{k}}^{-1} \mathrm{R}_{\mathrm{i}, \mathrm{k}}
$$

which is an estimate of the true but unknown value WPBS.

The D-vac underestimated immature and adult Lygus populations by factors of 4.06 and 1.16 , respectively, while the sweepnet underestimated them by factors of 12.77 and 3.65, respectively. (These estimates are made with 1974 Bartel data only, since the other fields lacked Lygus populations.) The D-vac was approximately three times as efficient as the sweepnet, and is clearly a better relative sampling method than the sweepnet, because it is less susceptible to the idiosyncrasies of the sampler (the are of swing, the vigor with which it is taken, the walking speed and the like).

While the conversion for Lygus was not perfect, it is valuable, since this species is one of the key pests in California cotton (Falcon et al., 1971). Accurate assessment of Lygus densities using some easily done relative method is desirable, if sound pest control recommendations are to be made. It is most unfortunate that the $\mathrm{D}$-vac and sweepnet results for the other species sampled were so inconsistent (Table 3 ), as the WPBS method may be too cumbersome to use in practical pest management.

\section{Factors influencing results of WPBS}

Selection of plants for sampling. The three alternative methods used to select plants were:

TABLE 3

POOLED REGRESSIONS OF WPBS, D-VAC, AND SWEEPNET COUNTS, USING DATA FROM ALL TEST FIELDS

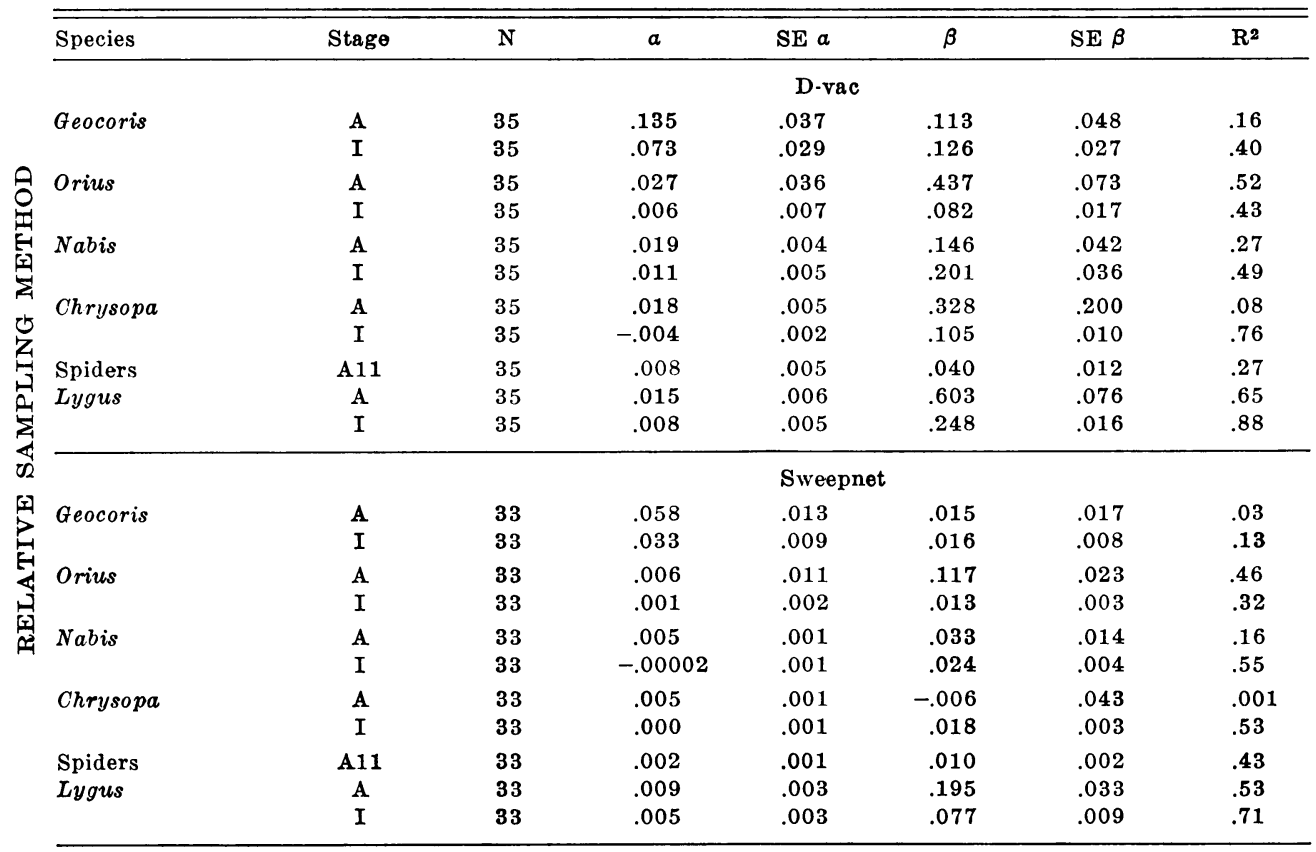




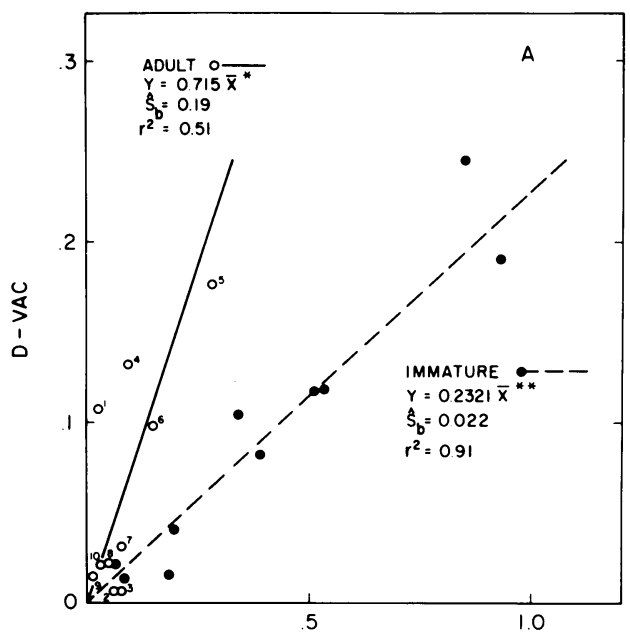

WHOLE PLANT BAG SAMPLE

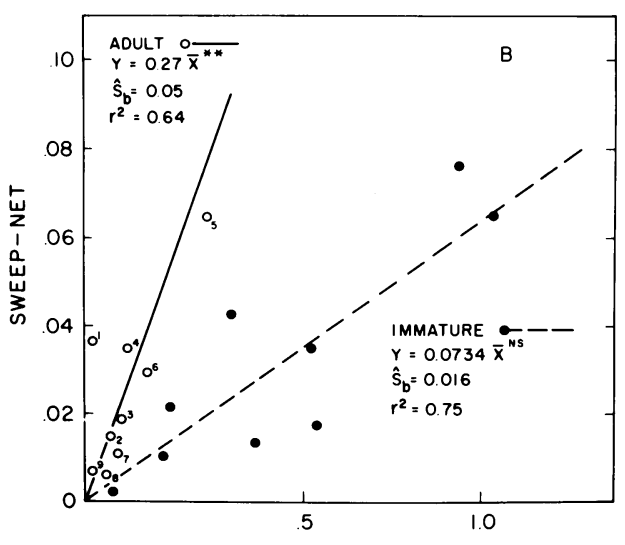

WHOLE PLANT BAG SAMPLE

Fig. 10. Plot of corresponding counts of Lygus hesperus immatures and adults using (A) D-vac and (B) sweepnet samples on WPBS for Bartel 1974. Regressions have been forced through the origin because $a$ is not significantly different from zero for any of the least squares regressions. Numbers above the adult symbols represent number of weeks from the beginning of sampling.

1) three adjacent plants in each of two adjacent rows (Fig. $1 \mathrm{Ba}$ );

2) two groups of three adjacent plants in the same row (Fig. 1Bb); and

3 ) six widely separated plants in the same row (Fig. 1Bc).
The Geocoris data for Bartel 1974 were used as an example only to show how the method of selecting plants influenced the population estimates. No inferences about Geocoris biology can be drawn from these analyses, hence similar analyses are not made for other species. The implicit assumption is that similar effects would occur when sampling for other species.

A comparison of the results of these three methods is shown in Table 4. Although the third method gave slightly higher population estimates than the other two, only in the case of immature Geocoris was the difference significant. This is probably due to an unconsciously biased choice of larger plants by the sampler. Although the position of the sample in the row was chosen at random, there were always several plants in approximately that position which might be sampled. Taking three adjacent plants reduces the number of decisions made by the sampler from six to two, and so reduces the opportunity for a biased choice. However, since widely separated plants are more quickly sampled, a scheme which retains this desirable characteristic, but reduces the chance of bias, may be advantageous. The simplest way to achieve this may be to sample not the plant initially chosen, but a plant separated from it by some interval-e.g., the fifth plant to the left of that originally chosen.

Number of plants sampled. Doubling and halving the number of plants sampled has no effect on the estimated values for population density, but did, as expected, affect their precision (Table 5). The data indicate that to reduce the standard error of the estimate of total Geocoris density to 10 percent of the mean, would in this set of samples require sampling about 200 plants. To reduce the standard error to 20 percent of the mean would require about 50 plants. The problem of decid- 
ing how many plants to sample in the general case is discussed in a later section.

\section{Distribution of predators within the field}

Systematic variation in density. Only spiders show any evidence of systematic variation in density within the field. Spiders in the 1974 Bartel field were significantly more dense in the most easterly rows of the field. Because several spider species are included in the samples, it is not known whether this variation is general or due to only a part of the spider fauna. With this single exception, there were no significant differences in population density among columns, rows, or rings for any of the species in any of the fields which were sampled. This was true regardless of the sampling technique used.

Aggregation patterns of active stages. Figures 11 to 16 show crowding (*) plotted against mean density $(\bar{x})$ for each of the species studied, using data from the WPBS. The intercepts $(\alpha)$ of these regression lines were, in general, not significantly different from zero, indicating that none of these species occurs in cohesive groups or colonies. In the figures, the regression of $\mathrm{x}^{*}$ on $\overline{\mathrm{x}}$ was therefore forced through the origin, so as to facilitate inter-specific comparisons. The distributions of all species show a significant degree of aggregation ( $\chi^{2}$ tests show that in all cases, significantly more points fall above, rather than below, the line predicted by a Poisson distribution). Geocoris adults were classified as to sex and instars, but the distributions of males, females and immatures were not different, nor was that of adults (Fig. 11). In Nabis (Fig. 13), Chrysopa (Fig. 14), and particularly Orius (Fig. 12) species there was a tendency (statistically nonsignificant) for immatures to be more aggregated than adults.
In general, for all species, the values of the regression coefficients $\beta$ (forced through the origin) range between 1.5 and 2.0 only Orius nymphs, as noted previously had consistently higher values. The variance about the unforced regression lines differed greatly from species to species and from field to field. For example, $r^{2}$ values for different species in the Bartel 1973 field range between .07 (Orius) and .94 (Chrysopa).

In some cases, where the species (or stage) concerned was at low density in a particular field throughout the season, the estimates of the regression parameters suffer from poor estimates of this population variance; such cases often have low $r^{2}$ values. Nonetheless, the overall conclusion is clear viz., the aggregation patterns of different species were similar. Moreover, the degree of aggregation was similar in different fields. This means that the same general sampling rules could be used for all the species studied here. None had a distribution so aggregated or so uniform as to require treatment as a special case.

Regressions of $\stackrel{*}{\mathrm{x}}$ on $\overline{\mathrm{x}}$ for sweep and D-vac data were found to show less aggregation than the WPBS results. In general the distributions did not deviate significantly from randomness. This result is to be expected, because single D-vac, or sweep sample, actually includes samples from at least 50 plants, thus the distributions resemble distributions of means, and their variances were consequently relatively low.

Aggregation patterns of Geocoris eggs. Geocoris egg densities were estimated both by WPBS and by visual counts (WPVS). Figure 17 shows crowding $\left({ }^{*}\right)$ plotted against mean density $(\overline{\mathbf{x}})$ for both methods. The regressions had significantly different intercepts $(\mathrm{P}<.05)$. That for the visual counts was not different from zero, while that for WPBS was significantly greater than zero. This suggests that 

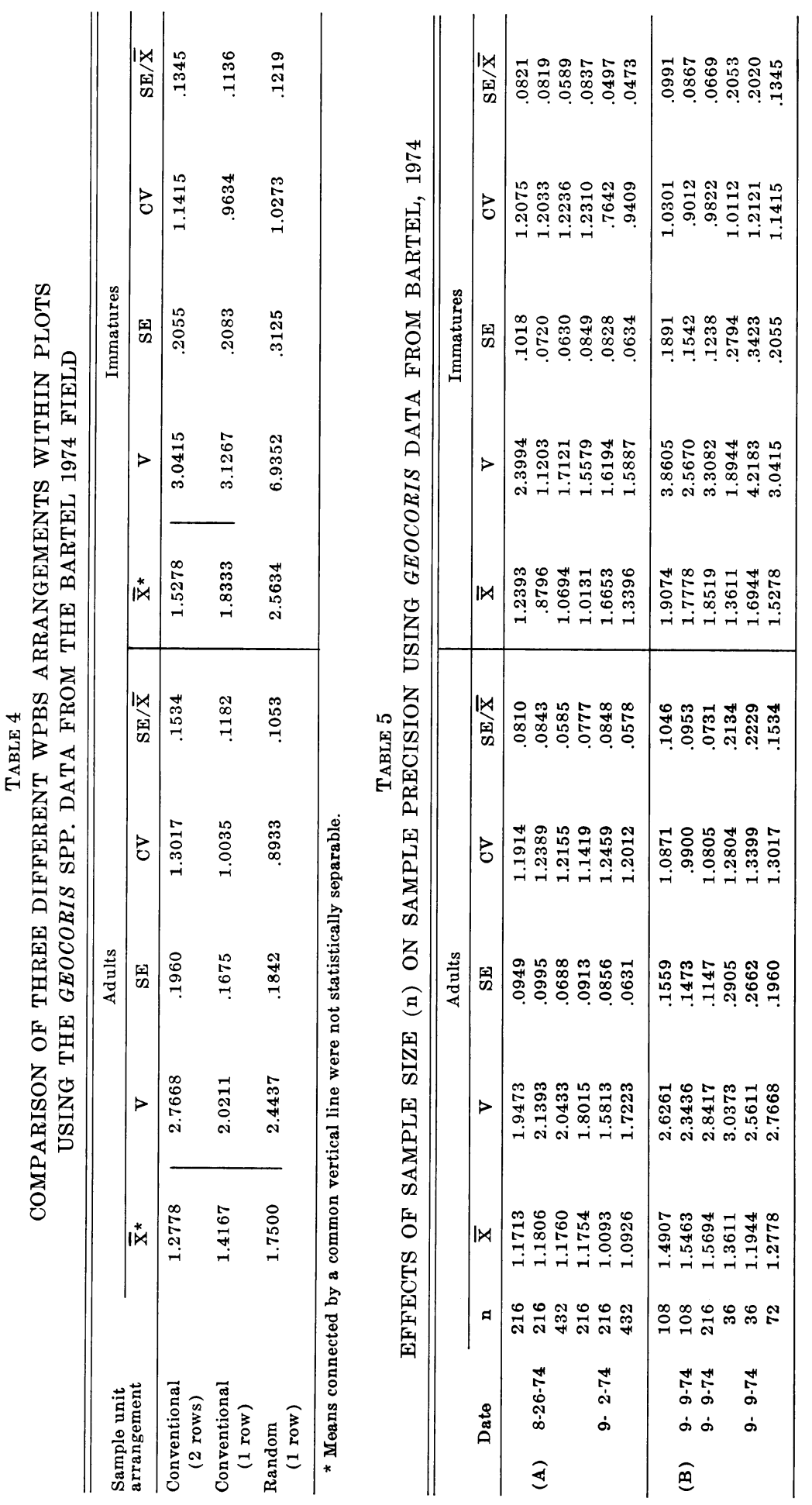


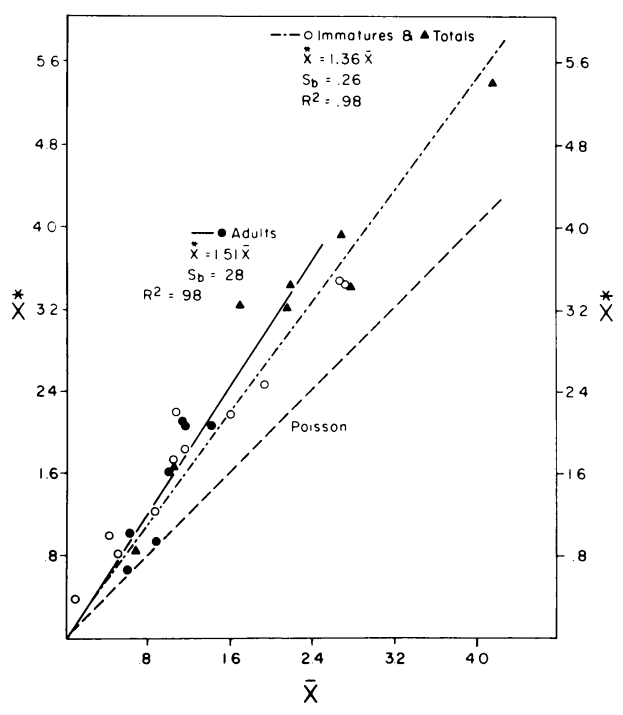

Fig. 11. Regression of crowding (*艹) on mean density $(\overline{\mathbf{x}})$ for immatures, adults, and total in. dividuals of Geocoris pallens.

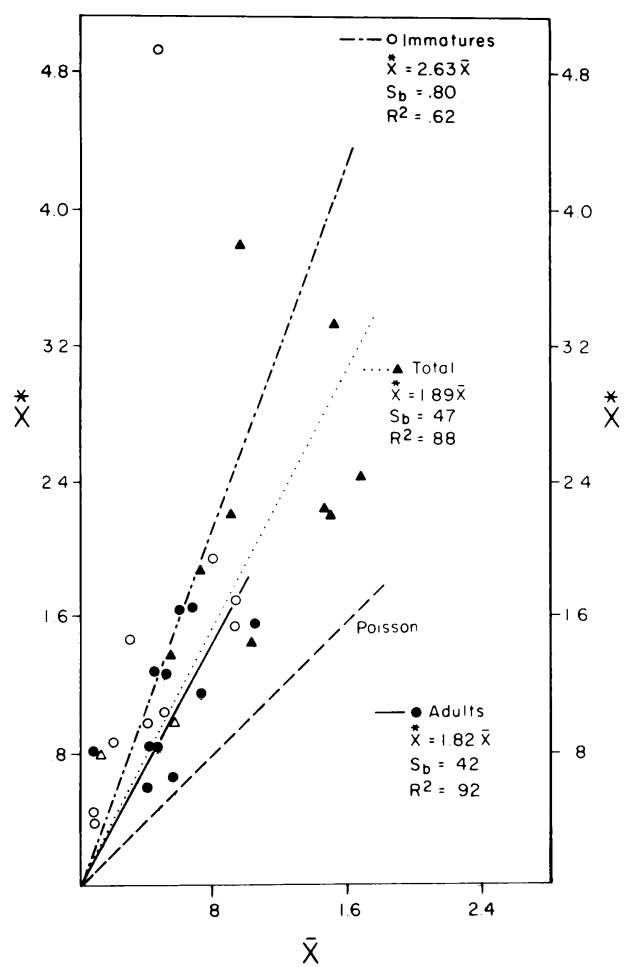

Fig. 12. Regression of crowding ( $\mathrm{x}$ ) on mean density $(\overline{\mathbf{x}})$ for immatures, adults, and total individuals of Orius tristicolor.

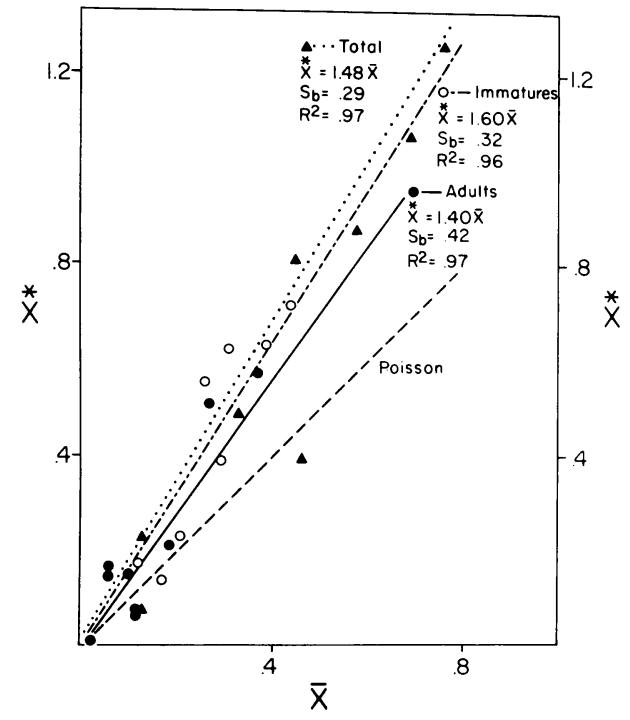

Fig. 13. Regression of crowding (像) on mean density $(\overline{\mathbf{x}})$ for immatures, adults, and total individuals of Nabis americoferus.

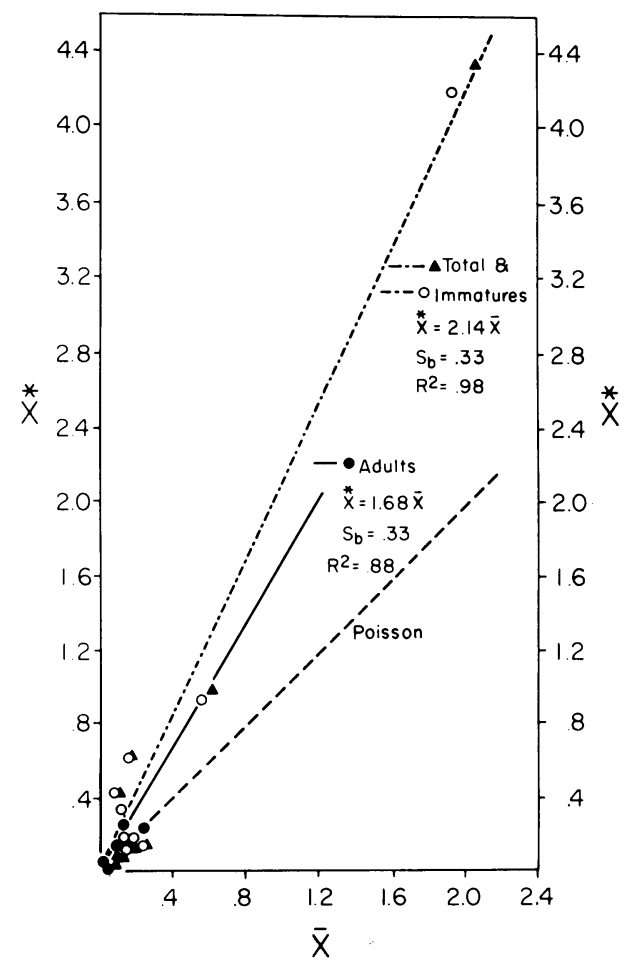

Fig. 14. Regression of crowding (*艹) on mean density $(\overline{\mathbf{x}})$ for immatures, adults, and total individuals of Chrysopa carnea. 


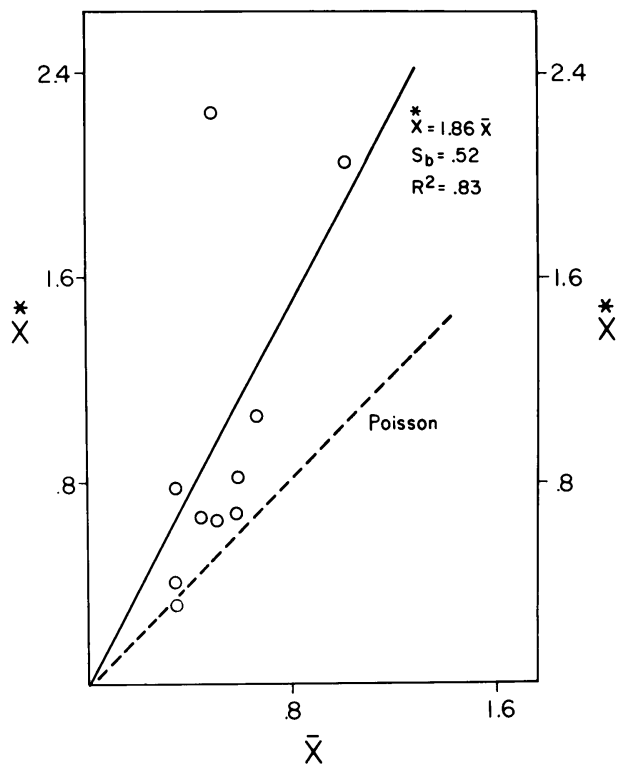

Fig. 15. Regression of crowding $(\stackrel{*}{\mathbf{x}})$ on mean density $(\overline{\mathbf{x}})$ for spiders.

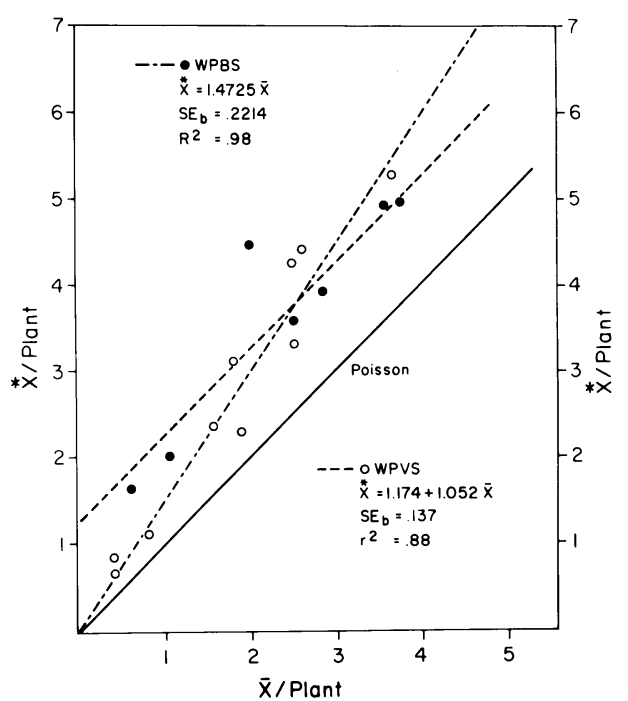

Fig. 17. Regression of crowding (*) on mean density $(\overline{\mathbf{x}})$ for Geocoris eggs.

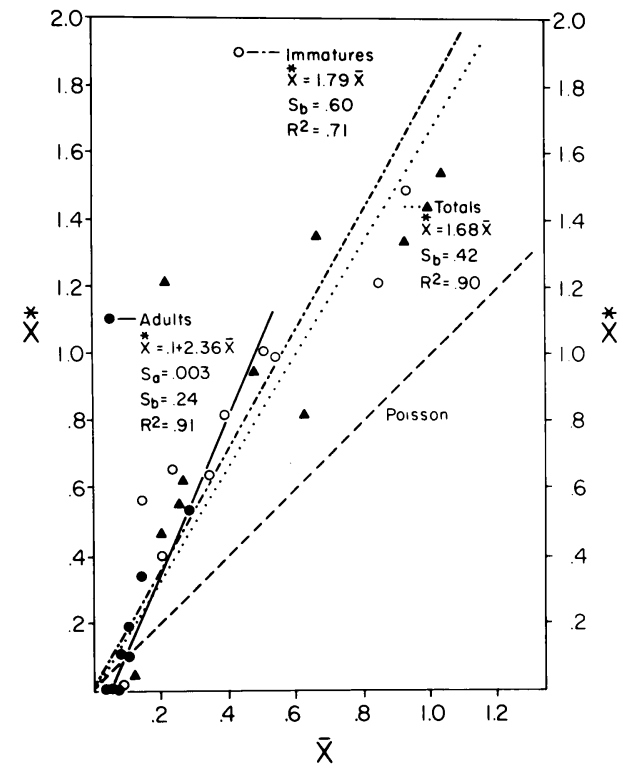

Fig. 16. Regression of crowding (*) on mean density $(\bar{x})$ for immatures, adults, and total individuals of Lygus hesperus.

Geocoris females tended to lay more than one egg on a single plant. The discrepancy among methods is probably due to the small proportion of the eggs found when plants are large-perhaps due to sampler fatigue. 


\section{GENERAL DISCUSSION}

\section{Comparison of sampling methods}

The objective stated in the introduction-to develop an absolute sampling method for cotton arthropods-was achieved for some stages and species using WPBS. This technique was most satisfactory for easily dislodged arthropods, specifically, for adult and immature Geocoris spp., Orius spp., Nabis spp., Lygus spp., larval Chrysopa and perhaps certain spiders. The method would work well for the larvae of loopers, beet armyworm, and other foliage feeding lepidoptera, and for boll weevil adults, but these tests remain to be made. It would not work well for organisms such as mites, larval boll weevil, pink bollworm, or eggs of Orius, Nabis, and Lygus, that adhere strongly to the plant, or are embedded in plant parts. Nor would it work well for lacewing adults, because these insects can fly at low temperatures and so frequently escape.

It is apparent that sweepnet and D-vac methods underestimated the numbers of both adult and immature insects present in the field. Occasionally, quite high densities of immatures remained completely undetected by these methods. This study, like that of Race (1960) found that D-vac samples generally gave higher estimates than did sweepnet samples. But a more serious deficiency of these techniques is that they generally do not even give the same general trends in population numbers as were given by the WPBS, a method that approximated an absolute sample. In several cases, the regression coefficient for the D-vac and sweepnet samples versus the WPBS was actually negative, though the evidence was not significant. Presumably, these discrepancies arose because-

1) The D-vac and sweepnet methods sampled only the terminals, so large proportions of the insects on the plants were uncatchable, and

2 ) these relative methods sampled a smaller fraction of a large plant than they did of a small one, and thus sampled different fractions of the population at different times on different plants.

The only exception to the generally poor performance of the D-vac and sweepnet methods when compared to the WPBS was Lygus spp., an insect that lives on the uper strata of the plant. Although these methods underestimate population numbers (immatures more seriously than adults) they gave the same population trends as did the WPBS for this species.

Counts of Geocoris spp. eggs were made in two ways-WPBS and whole plant visual counts. These eggs should be ideal for visual methods, since they are immobile, rather large, and hence easily observed. Nonetheless, in this study visual counts seriously underestimated egg numbers late in the season, when the plants were large and more difficult to search. This suggests that the results of this technique, which has also been used as an "absolute" sample in cotton by a number of workersKuehl and Fye (1970, 1972), Fye (1972), Pieters and Sterling (1974), Allen (1972), Hill et al. (1975), should be viewed with extreme caution when applied to older plants. It should be noted that WPBS, in fact, requires less time and effort than visual counts, especially on older plants.

There seems no good reason why WPBS could not be used routinely by researchers on cotton, though, as noted earlier, it may prove too cumbersome for the practical problem of determining treatment, unless relatively high precision is required. With very slight modifications, the technique could also 
be used on other field and vegetable crops, depending on the growth form of the plant, the planting pattern and stand density of the crop, and the behavior of the organism to be sampled.

\section{Species distributions and sampling rules for WPBS}

Species distributions. Only spiders showed any systematic variation in density within the cotton field. A similar homogeneity was reported by Kuehl and Fye (1970, 1972) and Fye (1972) for lepidopteran larvae in cotton. The spiders appeared to be the densest around the area where irrigation water drained off the field. Since they spend a good deal of time on the ground and in the trash, it is possible that either they float with the trash to the edge of the field, or that the accumulation of trash in this area makes for a more favorable spider habitat.

All species showed an aggregated distribution. It was difficult to compare the aggregation patterns revealed by the WPBS with the results of other studies of aggregation patterns in cotton, because workers have used different sampling techniques. Kuehl and Fye (1972), Allen (1972), Pieters and Sterling (1974), and Hill et al. (1975) used visual counts, Sevacherian and Stern (1972) used sweepnet counts, and Pieters and Sterling (1974) used D-vac counts. These techniques in our works gave different and often misleading results compared to absolute WPBS samples. The objectives of the cited studies were mainly to fit the observations to some statistical distribution (generally the negative binomial) and to derive a sequential sampling scheme to determine when the insect has reached some pre-determined critical density, that is, an economic or injury threshold for the pest. Our study has shown that the normally-used D-vac and sweepnet sampling techniques are wholly unsatisfactory for this purpose, except in the case of Lygus bugs. They are also of limited value as a means of establishing plant-to-plant distribution patterns, since distributions of sweepnet or D-vac samples behave like distributions of means; they tend to be normal. Although it is possible to calculate what degree of plant-to-plant aggregation would result in the observed values, the procedure is inaccurate and moreover requires a priori assumptions about the form of the distribution.

Our results agree with Kogan et al. (1974) who noted that in reporting such sampling studies, researchers generally must specify the type of crop, the sampling method, and the organism; otherwise, an adequate basis of comparison is lacking. In general, the use of the negative binomial parameters to characterize the distribution, although simple and convenient, seems a less meaningful biological procedure than Iwao's (1968) regression technique. No doubt future developments will improve the analytical process. But no degree of analytical sophistication will help much, if, as in the case of many D-vac, sweep, and visual counts in cotton, the data themselves are poor representations of the actual densities and distributions in the field.

Sampling rules for WPBS. On the basis of the cost and effort required, WPBS sampling of individual widely spaced plants is better than using contiguous plants. This, however, tends to bias counts upwards, perhaps because the sampler tended to choose larger plants. Allen and Gonzalez (1972) suggested sampling groups of 5 adjacent plants to overcome this problem, but such a procedure is not feasible for WPBS, because of the need to avoid disturbing the plants to be sampled.

The number of plants to be sampled depends on (a) the degree of accuracy required, (b) the density of the organism, and (c) the degree of aggregation of the organism. 


$$
\begin{aligned}
& 0-\beta=1.0 \\
& \Delta-\beta=1.5 \\
& 0-\beta=2.0
\end{aligned}
$$
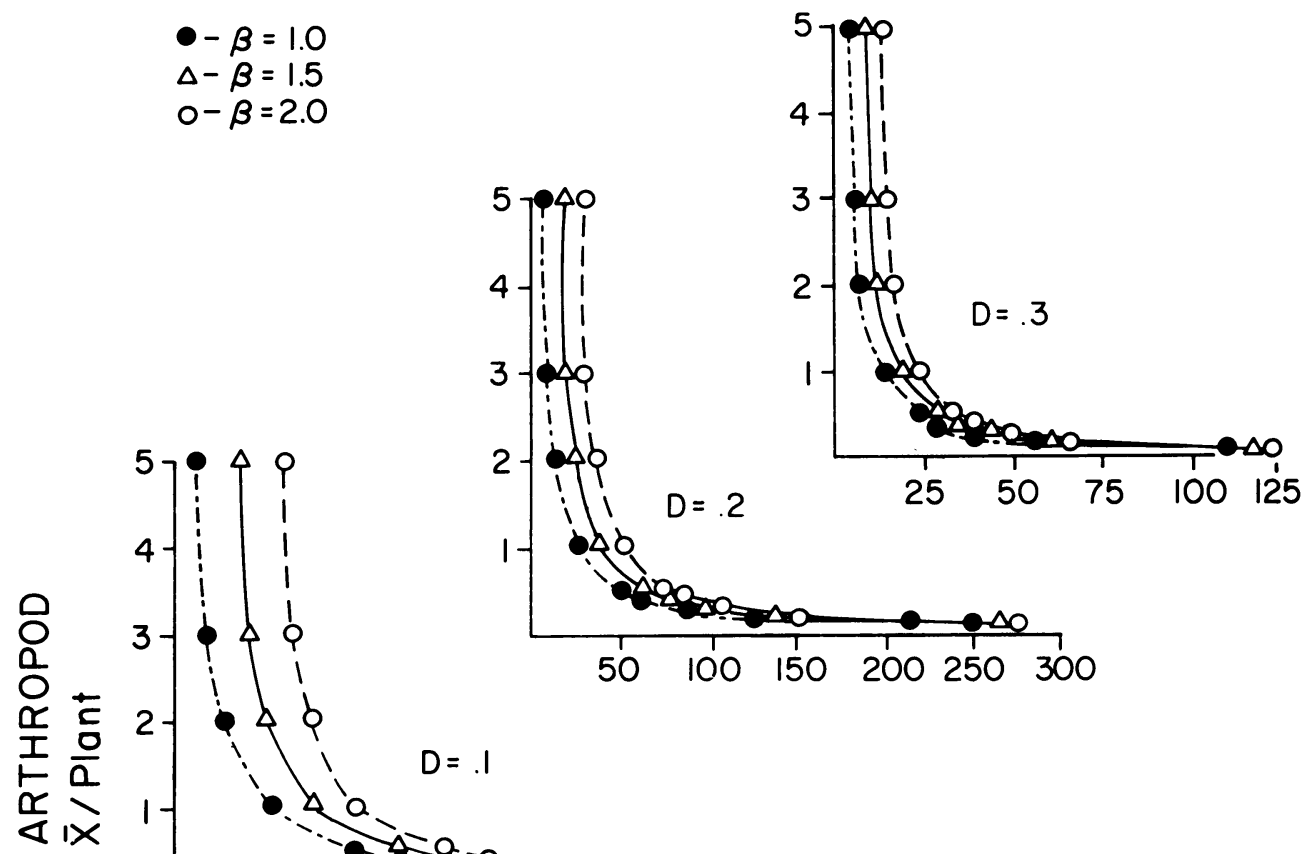

$D=.1$

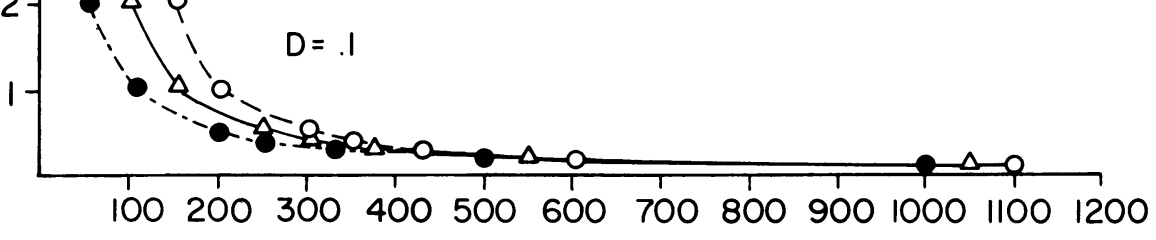

\section{Number of plants required}

Fig. 18. Number of samples required to achieve different levels of sampling accuracy $(\mathrm{D}=$ fraction of the mean) for different population densities and different degrees of aggregation $(\beta) . \beta$ is the slope of the regression of crowding $(\ddot{\mathbf{x}})$ on mean density $(\overline{\mathbf{x}})$, forced through the origin.

Sequential sampling schemes involve sampling until a decision, with defined precision, can be made concerning the density of an organism. The decision formula, as given by Iwao and Kuno (1968) is:

$$
\mathrm{n}=\left(t^{2} / \mathrm{D}^{2}\right)((\alpha+1) / \overline{\mathrm{x}}+\beta-1)
$$

$\mathrm{n}=$ sample size required

$t=$ student's $t$, giving the frequency with which a sample of size $n$ will give an estimate of precision $\mathrm{D}$ or better (e.g., if $\mathrm{t}=1$, frequency $=.67$ ).

$\mathrm{D}=$ accuracy required, as a fraction of the mean.

$\alpha, \beta=$ coefficients of the regression of * (crowding) on $\overline{\mathbf{x}}$ (mean).

In this study $\alpha$ was not different from zero, and $\beta$ varied between 1 and 2 depending on the field sampled and the specific organism being studied. Thus for the species studied the sampling rules would be similar, dependent only on the degree of precision required. Figure 18 shows the number of samples required to achieve accuracies (D) of 10,20 , and 30 percent of the mean, for values of $\beta=1.0,1.5$, and 2.0. For all the species studied, $\beta=1.5$ would generally be satisfactory, but if special caution was in order, one might assume $\beta=2.0$. It is apparent that to obtain an accuracy equal to 20 percent of the mean, a sample size of 50 would generally be more than adequate; at high population densities, 20 to 30 would be sufficient. 


\section{SUMMARY AND CONCLUSIONS}

A general review of the literature on sampling methods reveals that most methods employed by entomologists provide inadequate estimates of population numbers. The present paper described a "whole plant bag sample" (WPBS) as an approach to an "absolute" way to estimate population densities of various arthropods in cotton. The method may also be adapted for other types of crops. WPBS sample counts were compared to counts obtained using D-vac and sweepnet sampling methods, and WPBS counts of Geocoris spp. eggs also were compared with visual samples.

A comparison of the numbers detected by the two relative sampling methods and WPBS showed that the latter evaluates the populations of adult and immature Geocoris spp., Orius spp., Nabis spp., Chrysopa larvae and Notoxus adults, and perhaps spiders, with the greatest precision. The D-vac and sweepnet methods barely detected populations of immatures, spiders, or Notoxus. Because the relative methods usually did not even detect general population trends, it was not possible to develop a reliable factor to convert relative sample estimates to estimates of absolute density. The only exception was Lygus hesperus; the conversion ratios for $D$-vac and sweepnet were 1.0 and 4.0 for adults, and 4.0 and 13.0 for immatures. The counts must also be adjusted for plant density.

WPBS-derived phenology curves showed that the population densities of all species may vary considerably from field to field. There was no evidence of systematic variation in insect population densities within the cotton field, as indicated by comparisons between rows, columns, and rings of plants. All species had similarly aggregated distributions, as indicated by regressing crowding (*) on mean density $(\bar{x})($ Iwao, 1968). In all cases the y-intercept $(\alpha)$ was equal to zero, indicating that the "basic unit of contagion" of the distribution was the individual. The measures of aggregation were used to develop decision rules for sampling these species based on the degree of precision required.

In general, the WPBS method was the only reliable technique available for estimating the actual population densities of active arthropods in cotton; the two relative methods were both subject to errors.

\section{ACKNOWLEDGMENTS}

We wish to thank the following: Professor F. N. David for her very generous and excellent help in the design of the experiments; Dr. D. Gonzalez for suggesting the original problem; Dr. Thomas F. Leigh for his kindness during the progress of the research; and Mr. Hodge Black for his help in locating cooperative farmers; Mary Kolesar, Jumiko Goss, Clair Carrol,
James Voth, and Michael Dobrenen, who worked conscientiously for the project; and Anne Gutierrez, Carmen Peterson, and Sonia Byerly who performed most of the clerical work.

This work was supported by the California Planting Cotton Seed Distributors and the National Science Foundation Grant DEB 75-04223. 


\section{LITERATURE CITED}

Allen, J. D.

1972. Sequential sampling plans for the bollworm Heliothis zea. Environ. Entomol. 1: 771-80. Cochran, W. G.

1963. Sampling techniques. 2nd Ed., New York: John Wiley and Sons, Inc. 413 pp.

Davis, J. W., C. B. Cowan, JR., W. C. Watkins, JR., D. D. Lingren, and R. I. Ridgeway

1966. Experimental insecticides applied as sprays to control Thrips and the Cotton fleahopper. J. Econ. Entomol. 59:980-82.

Dietrick, E. J., E. I. SCHLinger, and R. VAN DEN Bosch

1959. A new method for sampling arthropods using a suction collecting machine and modified Berlese funnel separator. J. Econ. Entomol. 52:1085-91.

DIETRICK, E. J.

1961. An improved back pack motor fan for suction sampling of insect populations. J. Econ. Entomol. 54:394-95.

Falcon, L. A., R. van den Bosch, J. Gallagher, and A. Davidson

1971. Investigation of the pest status of Lygus hesperus in cotton in central California. $\mathbf{J}$. Econ. Entomol. 64:56-61.

Frazer, B. D., and N. E. Gilbert

1976. Coccinellids and aphids: a quantitative study of the impact of adult ladybirds (ColeopFye, R. E. tera: Homoptera, Aphididae). J. Ent. Soc. B. C. 73:33-56.

1972. Populations of lepidopterous larvae in outer and inner portions of a cotton field. J. Econ. Entomol. 65:287-88.

Gonzalez, D., D. A. Ramsay, T. F. Leigh, B. S. Ekhom, and R. van Den Bosch

1977. A comparison of vacuum and whole-plant methods for sampling predaceous arthropods on cotton. Environ. Entomol. 6:750-60.

Gutierrez, A. P., L. A. Falcon, W. Loew, P. A. Leipzig, and R. van Den Bosch

1975. An analysis of cotton production in California: a model for acala cotton and the effects of defoliators on its yields. Environ. Entomol. 4:125-36.

HarcourT, D. G.

1969. The development and use of life tables in the study of natural insect populations. Ann. Rev. Entomol. 14:175-96.

Hill, B. G., R. W. McNew, J. H. Young, and W. E. Ruth

1975. The effects of sampling-unit size in some southwestern Oklahoma cotton insects. Environ. Entomol. 4:481-90.

Iwao, S.

1968. A new regression method for analyzing the aggregation pattern of animal populations. Res. Popul. Ecol. 10:1-20.

IwAo, S., and E. KUNo

1968. Use of the regression of mean crowding on mean density for estimating sample size and the transformation of data for analysis of variance. Res. Popul. Ecol. 10:210-14.

1971. An approach to the analysis of aggregation patterns. In B. P. Patiel, E. C. Pielou, and W. E. Waters (Eds.), Statistical Ecology, Vol. 1: Spatial Patterns and Statistical Distributions. Penn. State Univ. Press, Univ. Park, pp. 311-35.

Kogan, M., W. G. Ruesink, and K. McDowell

1974. Spatial and temporal distribution patterns of the bean leaf beetle Cerotoma trifurcata (Foster), on soybeans in Illinois. Environ. Entomol. 3:607-17.

KuehL, R. O., and R. E. Fye

1970. Efficiency of grid stratification in cotton fields for cotton insect surveys. J. Econ. Entomol. 63:1864-66.

1972. An analysis of the sampling distributions of cotton insects in Arizona. J. Econ. Entomol. 65:855-60.

Leigh, T. F., D. Gonzalez, and R. van DEN Bosch

1970. A sampling device for estimating absolute insect populations on cotton. Econ. Entomol. 63:1704-06.

1971. Clam shell insect samples allows absolute insect population estimates. California Agriculture 25:3.

LLoyd, $\mathrm{M}$.

1967. Mean crowding. J. Anim. Ecol. 36:1-30.

Mendenhall, W., O. Lyman, and R. L. SchaefFer

1971. Elementary Survey Sampling. Wadsworth Pub. Co. Inc. 247 pp. 
MORRIS, R. F.

1955. The development of sampling techniques for forest insect defoliators, with particular reference to the spruce budworm. Can. J. Zool. 33:225-94.

1957. The interpretation of mortality data in studies of population dynamics. Can. Entomol. 89:49-69.

1960. Sampling insect populations. Ann. Res. Entomol. 5:243-64.

MORRIs, R. F., and C. W. BennetT

1967. Seasonal population trends and extensive census methods for Hyphantria cunea. Can. Entomol. 99:9-17.

Pieters, E. P., and W. L. Sterling

1973. Inferences on the dispersion of cotton arthropods in Texas. Environ. Entomol. 2:863-69.

1974. Aggregation indices of cotton arthropods in Texas. Environ. Entomol. 3:598-600.

RACE, S. R.

1960. A comparison of two sampling techniques for Lygus bugs and stink bugs on cotton. J. Econ. Entomol. 53:689-90.

Sevacherian, V., and V. M. STERN

1972. Spatial distribution patterns of Lygus bugs in California cotton fields. Environ. Entomol. 1:695-703.

ShePpard, M., and W. L. Sterling

1972. Effects of early season applications of insecticides on beneficial insects and spiders in cotton Tex. Agr. Exp. Sta. M.P.-1045. 14 pp.

Smith, J. W., E. A. Stadelbacher, and C. W. GautT

1976. A comparison of techniques for sampling beneficial arthropod populations associated with cotton. Environ. Entomol. 5:435-44.

Southwood, T. R. E.

1966. Ecological methods, with particular reference to the study of insect populations. London: Methuen and Co., Ltd., $391 \mathrm{pp}$.

Strickland, A. A.

1961. Sampling crop pests and their hosts. Ann. Rev. Entomol. 6:131-46.

VAN DEN BoSCH, R., and K. S. HAGEN

1966. Predacious and parasitic arthropods in California cotton fields. Calif. Agric. Expt. Sta. Bull. 820. $32 \mathrm{pp}$.

VARlex, G. C., and G. R. GRADwell

1960. Key factors in population studies. J. Anim. Ecol. 29:399-401.

1971. The use of models and life tables in assessing the role of natural enemies. In Huffaker, C. B. (Ed.). Biological Control. pp. 93-112. Plenum Press.

YAMANE, $\mathrm{T}$.

1967. Elementary Sampling Theory. New York: Prentice-Hall, Inc. 405 pp. 